\title{
V. NATION UND RELIGION
}

\author{
1. Paris: Zum monumentalen Disput \\ um die (a)religiöse Affinität der französischen Nation
}

In einer so weder für Deutschland noch für England zu beobachtenden monumental intensiven Form setzte nationale Selbstverständigung in Frankreich nach 1871 die Positionierung gegenüber religiösen Loyalitäten voraus. Es gehörte zu den Symptomen dieser diskursiven Dringlichkeit, daß zu den ersten öffentlichen Denkmälern, die nach 1871 im Pariser Stadtareal entstanden, 1874 die Reiterstatue Jeanne d'Arcs zählte und mit zwei weiteren Monumenten bis zur Jahrhundertwende zusätzliche Ehrungen jener legendären und schillernden Kultfigur erfolgten, deren Sinnstiftungspotentiale zwar über religiöse Assoziationen weit hinausreichten, sie aber dennoch zentral thematisierten. Am laizistischen Credo der republikanischen Nation arbeiteten sich parallel und in je neu spezifischer Verquickung mit dem Jeanne-Diskurs die Voltaire-Apologeten und Errichter seiner Denkmäler ab, so daß sich vor allem aus dem zeitgenössischen komplementären Bezug dieser beiden Figuren das Konnotationsfeld erschloß, in das der Nationsbegriff im Blick auf religiöse und konfessionelle Sinnbezüge gestellt wurde. Erst im Anschluß an ein solchermaBen aufbereitetes Bedeutungsterrain folgten Ende der 1880er Jahre weitere Denkmäler für ausgewiesenes konfessionell oder säkular identifiziertes Personal, dessen Monumentalisierung nicht selten unter eklat- und affrontartigen Bedingungen zustandekam und den Diskurs überwiegend in polemischaggressivem Ton und im Stile einer ausgewiesenen Exklusionsthetorik fortsetzte.

\subsection{Konvulsion, Dissoziierung und Kollision nationaler Selbstbild-Entwürfe im Spiegel der Jeanne d'Arc-Denkmäler}

Nachdem ein (bild)programmatischer Diskurs über die Jeanne d'Arc-Figur längst Tradition hatte ${ }^{1}$, zeichnete sich mit Gründung der Dritten Republik eine Hochphase des nationalen Kults um die Jungfrau von Orléans ab, die freilich

1 Vgl. z.B. E. de BOUTEILLER, Notes iconographiques sur Jeanne d'Arc, Paris 1879. Vgl. Gerd KRUMEICH, Eine oder mehrere Jeannes?, in: Marieluise CHRISTADLER (Hg.), Deutschland - Frankreich. Alte Klischees - neue Bilder, Duisburg 1981, S. 25-40; Michel WINOCK, Jeanne d'Arc, in: NORA (Hg.), Les lieux III, Bd. 3, S. 674-733. 
rasch zum Projektionshintergrund unversöhnlich gegensätzlicher Nationsentwürfe geriet.

Zu den ersten öffentlichen Denkmalprojekten der Dritten Republik zählte in der Tat die Errichtung einer Reiterstatue für Jeanne d'Arc 1874 auf der Place des Pyramides an der Rue de Rivoli. Die Aufstellung am frühen Nachmittag blieb so unauffallig, daß sie kaum als »inauguration officielle« wahrgenommen wurde ${ }^{2}$. Erst vier Tage nach der Aufstellung nahm Le Temps von der Statue Notiz, pries sie ungeachtet vielfacher Kritik an der künstlerischen Ausfuihrung des Werks ${ }^{3}$, als wune des plus pures de nos gloires nationales« und betonte die beachtlichen Bekundungen populärer Loyalität, als die das Blatt die Niederlegung mehrerer Kränze mit violetten und weißen Blumen und Gebinde am Sockel und am einrahmenden Gitter der Statue wertete ${ }^{4}$. Indem ausdrücklich auf die historiographische Abhandlung Jules Michelets verwiesen wurde, um Schicksal und Bedeutung der Figur zu vergegenwärtigen, propagierte der Temps die romantisch-verklärende, republikanische Variante des Jeanne-Kults. Seit den 1820er Jahren erblickte die republikanische Historiographie Frankreichs in der Jungfrau von Orléans immer mehr die »fille du peuple«, die weder göttlicher Eingebung noch monarchischer Überzeugung, sondern dem Ziel der Rettung ihres Vaterlandes gefolgt, am Ende von ihrem König verstoßen und von ihrer eigenen Kirche auf den Scheiterhaufen gebracht worden sei ${ }^{5}$. Michelet ${ }^{6}$ zählt zu den Protagonisten dieser antimonarchischen und antiklerikalen Version der Legende, die Jeanne als volksnahe und säkulare »héroïne et (...) libératrice de la France « ${ }^{7}$ und um ihres beispiellos opferbereiten Patriotismus willen würdigte. Nur in der moderaten Interpretati-

2

3 Vgl. Paul BizouARD, La »Jeanne d'Arc« de la Place des Pyramides, in: L'Artiste, JanuarMärz 1899 (69 année), S. 209-213; F.E. DESNOYERS, L'Iconographie de Jeanne d'Arc, Orléans, ${ }^{2} 1893$, S. 19-21.

4 Vgl. Le Temps, 26. Februar 1874, S. 2.

5 Vgl. u.a. Le Petit Journal, 7. Mai 1878, S. 1, zur Fête de Jeanne d'Arc in Orléans. Vgl. Gerd KRUMEICH, Joan of Arc between right and left, in: TOMBS (Hg.), Nationhood, S. 6373, hier S. 64-66; DERS., Jeanne d'Arc-Kult und politische Religiosität in Frankreich nach 1870, in: Wolfgang SCHIEDER (Hg.), Religion und Gesellschaft im 19. Jahrhundert, Stuttgart 1993 (Industrielle Welt, 54), S. 318-331, hier S. 323. Zum Pariser JeanneReiterstandbild GLDEA, The Past in French History, S. 154-157; BOIME, Hollow Icons, S. 88-100.

6 Vgl. WINNOCK, Jeanne d'Arc, S. 701f.; Gerd KRUMEICH, Romantische Sensibilität und politisches Engagement. Die Entdeckung Jeanne d'Arcs im 19. Jahrhundert, in: Gangolf HÜBNGER, Jürgen OSTERHAMMEL, Erich PELZER (Hg.), Universalgeschichte und Nationalgeschichten, Freiburg i.Br. 1994, S. 179-194, hier S. 191f. Als Quintessenz der Michelet-nahen republikanischen Jeanne-Deutungen vgl. v.a. Art. Darc, Jeanne, in: Pierre LAROUSSE, Grand dictionnaire universel du $\mathrm{XIX}^{e}$ siècle français, historique, géographique, mythologique, bibliographique, littéraire, artistique, scientifique, $\mathrm{Bd} .6,1^{\mathrm{e}}$ partie, Paris [1870] ND 1982, S. 106-115.

7 Le Petit Journal, 7. Mai 1878, S. 1. 
onsvariante, in der etwa Le Petit Journal die Legende vertrat, gehörte die Figur zunächst einmal allen Franzosen, die sie - patriotisch - als »libératrice« oder religiös - als »sainte« verehren oder gar kanonisieren mochten ${ }^{8}$. Freilich enthielt das Deutungsmuster polemischen Zündstoff, indem es aus konservativer Sicht Kirche und Monarchie gleichermaßen diskreditierte.

Im Univers brach sich dagegen massive antirepublikanische, katholischorthodoxe Polemik in einem Artikel des Comte Guillaume de Sabran-Pontevès gegen die Aneignung der Kultfigur durch die Republik Bahn: »Jeanne d'Arc n'appartient pas à la France nouvelle (...), mais tout à fait à l'ancien régime«" Womöglich, so wurde gespottet, begann die Republik aber auch schon an ihren eigenen "dogmes nationaux « zu zweifeln und borgte hier also Orthodoxien ganz anderer Provenienz, um sich zu legitimieren. Den ironischen Einlassungen folgte eine mit Verve vorgetragene Version des royalistischen und katholischen Jeanne-Kultes, wie sie die französische Historiographie schon seit dem ausgehenden Mittelalter und während der langen Phase der absolutistischen Monarchie bereitgehalten hatte. Daß eine offizielle Einweihungszeremonie vermieden worden war, hatte demnach nur den einen Grund, die Revitalisierung der wahren »légende endormie ${ }^{10}{ }^{2}$ zu meiden: »Jeanne d'Arc rappelle trop crûment Charles VII. Là est vraiment le tort de la Pucelle.« Der Kern der Jeanne-Legende, der nämlich im göttlichen Auftrag zur Rettung des Königtums bestand, den sie erfüllte, indem sie Charles zur Krönung nach Reims führte, war der Republik dieser Einschätzung nach zuwider. Die gleichsam verstohlen aufgestellte Statue sollte ausreichen, die Idee einer wressurection pour la France « $z u$ assoziieren, die dann freilich nicht der Monarchie, sondern der Republik zugute kam. De Sabran-Pontevès verglich die solchermaßen karikierte Strategie mit dem Verfahren bei der Wiedererrichtung der Vendômesäule: auch hier eignete sich die Republik seiner Überzeugung nach fremde Legenden und Symbole an. Im Falle der Jeanne-Statue aber werde dies nicht verfangen, weil diese dauerhaft daran erinnerte, daß Frankreichs Heil damals wie heute in der Königskrönung lag $^{11}$. Die unverhohlen entwickelte Utopie von der monarchischen Rettung Frankreichs, mit der nicht zuletzt wehmütig auf den gescheiterten Versuch der Restauration der Monarchie von $1873^{12}$ angespielt zu werden schien, gipfelte in einen aggressiven Aufruf zum Denkmalsturz: Der Errichtung der »statue bénie« der Jeanne würde nun noch die Niederwerfung der »statue maudite« ihres ruchlos blasphemischen Kritikers

8

Vgl. ibid.: »Jeanne d'Arc appartient à tous les Français. Que les patriotes célèbrent la libèratrice! Que les catholiques puissent vénérer la sainte!«

9 Vgl. auch zum Folgenden L'Univers, 14. Mai 1874, S. 4; L'Union, 19. Februar 1871, S. 3; ibid. 21. Februar 1874, S. 1; Le Monde, 24. Februar 1874, S. 3.

${ }^{10}$ Ibid.

"Vgl. ibid.

12 Vgl. MAYEUR, Les débuts de la III ${ }^{\mathrm{c}}$ République, S. 29-30 
Voltaire folgen müssen ${ }^{13}$. Die Stilisierung Voltaires zum handfesten Feindbild und damit die Exklusion republikanisch-laizistischer Sinnzuschreibungen auf die Nation hin gehörten damit konstitutiv zum konservativen Jeanne-Kult. De Sabran-Pontevès schlo $B$ mit einer hymnischen Würdigung der Jeanne, die »'Église« und »la Patrie« vereine und deren »revanche« und »vengeance« mit dem Reiterdenkmal schon in greifbare Nähe gerückt sei. Neben Kirche und monarchischem Patriotismus erwies sich somit zuletzt auch die Revancheidee als konstitutiv für den konservativen Nationsentwurf, zu dem die Jeanne-Figur Anlaß bot ${ }^{14}$. Ebenso begriff Évariste Bavoux Vendômesäule und Jeanne d'Arc-Statue als "manifestations d'un même sentiment (...) de notre douloureuse humiliation sous le poids de nos récents désastres ${ }^{15}$ und damit als konstitutiven symbolischen Teil der Bewältigung des Niederlagentraumas von $1871^{16}$. Schließlich brachte die Säule Bavoux zufolge eine »muette protestation non pas seulement contre l'invasion étrangère, mais aussi contre le double crime du 4 Septembre et du 18 Mars, solidairement complice l'un de l'autre $\alpha^{17}$ vor. Mit der unterschiedslosen Disqualifizierung des Beginns der Pariser Kommune am 18. März 1871 und der Ausrufung der Dritten Republik am 4. September 1870 optierte der langjährige Apologet des Empire Bavoux ebenso klar für eine antilinke wie eine antirepublikanische Nationskonzeption, als deren monumentalen Garanten er die Vendômesäule nicht anders als die Jeanne-Statue erachtete.

Unter anderen Vorzeichen spielten auch republikanische Kommentatoren mit dieser Parallelisierung. Solange in den frühen 1870er Jahren eine entsprechende Entscheidung über die auf der Vendômesäule zu plazierende Statue noch nicht definitiv gefallen war, hofften sie gelegentlich auf die Anbringung einer France-Allegorie auf der Säulenspitze, als deren inspiriertes Spiegelbild die Jeanne-Statue erschien, die das republikanische Frankreich und den "peuple« rettete ${ }^{18}$. Die Triaskonfiguration der Kultfiguren, in der das zeitgenössische Argument konservativer wie republikanischer Prägung die Jeanne-Figur einerseits neben die Napoleon I.- oder France-Gestalt auf der Vendômesäule und das Voltaire-Bild andererseits stellte, dokumentierte die zentrale Bedeutung

Vgl. L'Univers, 14. Mai 1874, S. 4: »L'cuvre (...) ne serait qu'incomplète, si l'érection de la statue bénie [i.e. die Statue Jeannes, H.R.] n'était tôt ou tard suivi du renversement de la statue maudite [i.e. die Statue Voltaires, H.R.] (...) La statue sera donc renversée."

$14 \mathrm{Vgl}$. auch [An.,] Statue de Jeanne d'Arc, o. O. 20 février 1874 [up]; L'Union, 21. Februar 1874 , S. 1.

15 Évariste BAvouX, Les Monuments à Paris. La Colonne Vendôme et Jeanne d'Arc, in: L'Artiste, 1.August 1874, S. 105-115, hier S. 105.

${ }^{16}$ Vgl. DERS., Les Monuments de Paris. La Colonne Vendôme et Jeanne d'Arc, Paris 1874, S. 11-13.

17 DERS., Les Monuments, in: L'Artiste, s.o., S. 105.

18 Vgl. Eugène LÉVÉQUE, A propos de la Colonne Vendôme restaurée moins le couronnement et de la Statue élevée à Jeanne d'Arc près des Tuileries, Paris 1874, S. 4, 8-11. 
eines denkmaltopographischen Wirkkontextes, in dem nationale Sinnzuschreibungen je neu zustande kamen.

Die kontroversen Rezeptionsmuster gipfelten 1878 in heftigen Überwerfungen. Zwar war die republikanische Regierung bis dahin aus dem monarchischen Staatsstreichversuch vom Mai des Vorjahres gestärkt hervorgegangen und in eine Phase der innenpolitischen Konsolidierung eingetreten ${ }^{19}$, die erst allmähliche Stabilisierung der Republik wurde aber weiterhin von demonstrativen Zeichensetzungen begleitet. Als 1878 mehrere Feiern anläßlich des Centenaire von Voltaires Todestag am 30. Mai stattfanden, die dem Exponenten der aufgeklärt-säkularen Republik galten ${ }^{20}$, wuchs parallel dazu auch der öffentliche Zuspruch zu den Feierlichkeiten zugunsten der Pucelle, die in Orléans bereits Anfang Mai begonnen hatten ${ }^{21}$. Wenige Tage bevor sich die Kollision zwischen den beiden Kulten abzeichnete, verbot die Regierung nun definitiv sowohl öffentliche Voltaire-Feiern als auch geplante Kranzniederlegungen vor dem Pariser Denkmal der Jeanne d'Arc ${ }^{22}$. Unter dem Eindruck des Disputs entwarf der Constitutionnel beschwichtigend die Vision einer Nation, die es verstünde, eine »fête nationale« unter Wahrung des »tolérance«-Gebots zu veranstalten, indem sie jeder »secte« und "parti« den Kult ihrer grands hommes ohne gegenseitige Diffamierung gestattete: "Nous rêvons une ère où Paris offrira en cent endroits divers, les statues des hommes qui ont fait la France et qui perpétuent sa gloire, son prestige, son ascendant intellectuel sur le monde civilisé. $\kappa^{23}$ Damit wurde erstmals die Inszenierung monumentaler Kultfiguren und ihr topographisches Arrangement im öffentlichen Areal der Hauptstadt nicht als exklusiver Anspruch auf Deutungsmonopole, sondern als wünschenswerte Symbolvielfalt und Indiz der "nation tolérante« gewertet, die die Pluralität nationaler Identitätsstifter zulie $\beta^{24}$. Dennoch schritten am 30. Mai Polizeikräfte gegen Demonstrationsversuche am Jeanne-Denkmal ein und entfernten verbotenen Kranzschmuck ${ }^{25}$. Die angespannte Lage in Paris lenkte die Kultbewegung auf Domrémy um, wo Anfang Juli feierliche religiöse Pilgerzüge stattfanden; auch hier blieb aber die Kollision unvermeidlich, und republikanische »libre penseurs« kündigten Gegendemonstrationen $\mathrm{an}^{26}$.

19 Vgl. MAYEUR, Les débuts, S. 35-48; MOLLIER, GEORGE, La plus longue des Républiques, S. 65-118.

gl. dazu das folgende Kapitel.

${ }^{21} \mathrm{Vgl}$. Le Petit Joumal, 7. Mai 1878, S. 1; ibid. 20. Mai 1878, S. 1; Le Monde, 24. Mai 1878, S. 2; ibid. 27/28. Mai 1878, S. 1.

22 Vgl. Le Monde, 29. Mai 1878, S. 1.

${ }^{23}$ Le Constitutionnel, 30. Mai 1878, S. 1; ibid. 31. Mai 1878, S. 1.

${ }^{24} \mathrm{Vgl}$. aber doktrinär Le Monde, 29. Mai 1878, S. 1; L'Union, 8. Juli 1878, S. 1 [Mayol DE LUPÉ].

25 Vgl. Le Monde, 31. Mai 1878, S. 1.

26 Vgl. L'Union, 11. Juli 1878, S. 1. 
Aus der Mitte des mehrheitlich republikanischen Conseil Municipal de la Ville de Paris heraus wurden Versuche unternommen, den Jeanne-Kult zumindest um das Pariser Denkmal auf der Place des Pyramides verbindlich für eine republikanisch-säkulare Version in Beschlag zu nehmen. In diesem Sinne unterbreitete man den Vorschlag, die Sockelinschrift um die Widmung zugunsten der whéroïne de la défense nationale au quinzième siècle, (...) la fille du peuple, abandonnée par son roi qui lui devait sa couronne, trahie et livrée par la noblesse, jugée et condamnée par le clergé « zu erweitern ${ }^{27}$. Die Jungfrau von Orléans sollte so als Märtyrerin klerikalen und royalistischen »fanatisme« erinnert und ihr Denkmal nicht länger zu »démonstrations factieuses « gegen die republikanische Regierung mißbraucht werden können ${ }^{28}$. Der Vorschlag tauchte allerdings später nicht wieder auf. Damit war die definitive Autorisierung eines laizistisch-republikanischen Jeanne-Kults und die Exklusion von Monarchie und Kirche aus der über Jeanne assoziierten Nationsidee vorerst mißglückt.

Die Wechselfälle des reaktivierten Jeanne-Kults und ihre Konsequenzen für den nationalen Diskurs schätzten zeitgenössische Kommentare längst luzide ein. So analysierte der Journalist, Historiker und Kunstkritiker Jacques de Biez die Jeanne-Gestalt als zunächst vergessene Konsensfigur, die während des Zweiten Empire von der »legende napoléonienne« verdrängt worden $\operatorname{sei}^{29}$, nun aber, über der Zäsur von 1870/71, den "peuple français« über allen »désordre des circonstances « hinweg wieder zusammenführen und ihm, im Zweifel über seine eigene Identität ${ }^{30}$, eine Zukunftsdimension erschließen sollte ${ }^{31}$. Statt dessen war sie zum Kristallisationspunkt rivalisierender Sinnstiftungen geworden: "tous les partis se [réclament] d'elle. (...) Chacun [prône] sa Jeanne d'Arc avec la persuasion intime que celle qu'il défend est la meilleure (...). Des statues [s'élèvent] un peu partout ${ }^{32}$. Der republikanischen Aneignung des JeanneKults gegenüber, mit der ihm die Figur laizistisch gewendet und damit verfremdet schien, blieb der antisemitische Rechtsnationale de Biez reserviert: won a construit une Jeanne d'Arc très acceptable pour les esprits émancipés par la Révolution (...). Cette Jeanne d'Arc devient une figure nouvelle ${ }^{33}$. Dennoch sah er in der Revitalisierung und Transformation der Legende die eigentliche Schubkraft des neuen Kults, denn Heldentat und Martyrium boten sich auch ohne religiöse Konnotation als Parabel auf die jüngste Vergangen-

27

28

29

\section{0}

31

32

33 Ibid S 409

Vgl. ibid.

lbid. S. 406.

bid. S. 409.

Séance du 13 juillet 1878, in: CMPV, Année 1878, S. $607 f$.

Vgl. Jacques DE BIEZ, E. Frémiet, in: L'Artiste, Dezember 1893, S. 401-425, hier S. 410

Vgl. ibid. S. 405: „Ce pauvre peuple ne sait plus au juste ce qu'il est, s'il est Français ou simplement vaincu. «

Vgl. ibid. S. 403-405. 
heit der französischen Nation an und stellten mit der Revanche-Assoziation deren Rehabilitierung in Aussicht.

Auch zwei weitere Jeanne d'Arc-Denkmäler in Paris wurden nicht öffentlich enthüllt und kamen auf Initiativwegen zustande, die weithin im Dunkeln blieben. Im Oktober 1891 wurde eine der Stadt gehörende Statue der »Jeanne d'Arc libératrice« am Boulevard Saint-Michel aufgestellt ${ }^{34}$. Im Mai 1900 folgte ein Reiterstandbild auf der Place St-Augustin ${ }^{35}$. Ebensowenig feierlich installiert wie das erste Jeanne-Monument, wurden beide eher am Rande in die öffentliche Jeanne-Rezeption einbezogen. Die Deutungskontroverse der Vorjahre hielt unterdessen unvermindert an. Versuche einer republikanischen Inbesitznahme wie derjenige Joseph Fabres, der in der Assemblée Nationale für die Verankerung eines Nationalfeiertags zum öffentlichen Jeanne-Gedenken am 30. Mai warb, und dabei auf eine dezidiert antiklerikale Heldin zielte, blieben zunächst folgenlos ${ }^{36}$.

Kultkonflikte kulminierten währenddessen weiterhin am ehesten vor dem Jeanne-Denkmal an der Place des Pyramides. So versammelte sich dort am 7. Mai 1894 die Association de la Jeunesse catholique, schmückte das Monument mit einem von einer Trikolore umwundenen Kranz und begrüßte die Ansprache ihres Präsidenten de Roquefeuille, der die Rettung Frankreichs durch die religiös inspirierte Pucelle pries und die einhellige Aufnahme eben dieser Version der Legende als Grundlage der wconcorde entre tous les Français« empfahl $^{37}$. Ende Mai 1894 hingegen legte die Loge Alsacienne-Lorraine am Denkmal einen Kranz nieder, dessen Spruchband Jeanne als whérétique et relapse, abandonnée par la royauté, brûlée par l'Église« titulierte. Kurz darauf kam es zu Tumulten und Inhaftierungen und einer neuerlichen Kranzniederlegung durch katholische Studenten ${ }^{38}$. Ähnlich gestaltete sich die Aktion im Mai 1907, als die Freidenker (Libre Pensée) vor der Statue auf der Place StAugustin einen Kranz mit der Aufschrift Associations des Libres Penseurs à Jeanne d'Arc brûlée par les prêtres niederlegten, um die inzwischen weiter

34 Vgl. L'Artiste, November 1891, S. 395.

35 Vgl. Bulletin de la Société de l'Histoire de Paris, $27^{\mathrm{c}}$ année (1900), Paris 1900, S. 174, 175.

${ }^{36} \mathrm{Vgl}$. Joseph FABRE, Les bourreaux de Jeanne d'Arc et sa fête nationale. Notices sur les personnages du procès de condamnation. Documents sur la fềte du patriotisme, Paris 1915, S. 119-139; DERS.: Jeanne d'Arc. Libératrice de la France, Paris o. J. [1883]. Unterstützung erfuhr FABRE im Conseil Municipal, vgl. Séance du 17 Juin 1912, in: CMPV, Année 1912, $1^{\text {ère }}$ partie, S. 1206-1211. Vgl. auch Abbé SIRECH, Jeanne d'Arc et le patriotisme contemporain. Discours prononcé à Lyon, le 19 mai 1901 en l'Église Sainte-Blandine, Lyon 1901. Vgl. zum 1919/20 institutionalisierten Nationalfeiertag KRUMEICH, Joan of Arc, S. 69; DERS., Jeanne d'Arc in der Geschichte. Historiographie - Politik - Kultur, Sigmaringen 1989 (Beihefte der Francia, 19), u.a. S. 190, 197; zur Vorgeschichte des Feiertags vgl. SANSON, La »Fête de Jeanne d'Arc «, passim.

37 Vgl. Le Monde, 8. Mai 1894, S. 2.

${ }^{38} \mathrm{Vgl}$. ibid. 1. Juni 1894, S. 3. 
verstärkten Anläufe der katholischen Kirche zur Inbesitznahme der Figur im Zuge einer schrittweisen Kanonisierung Jeannes zur Heiligen zu brüskieren ${ }^{39}$.

Dem republikanischen stellte sich je neu der monarchistische Zugriff auf die Kultfigur entgegen. So versammelten sich 1909 parallel zu den Feierlichkeiten anläßlich der Seligsprechung Jeannes durch die katholische Kirche in NotreDame $^{40}$ royalistische Komitees in Paris zu einem Bankett und wollten mit Lilienbannern und dem weißen Banner der Jeanne d'Arc unter Hochrufen auf die Monarchie und gegen Ministerpräsident Clemenceau zur Place de la Nation ziehen ${ }^{41}$. Die Ordnungskräfte waren jedoch angewiesen, die Embleme notfalls gewaltsam zu konfiszieren, und so endete dieser Demonstrationsversuch nach Tumulten mit zahlreichen Verletzten auf beiden Seiten und mit 18 Festnahmen $^{42}$. Während weitere Demonstrationen vor dem Denkmal an der Place des Pyramides friedlich blieben, kam es direkt vor dem Reiterdenkmal an der Place St-Augustin zu handgreiflichen Auseinandersetzungen zwischen "manifestants royalistes« und »socialistes«, die beide den Tag über die Statue mit Kränzen geschmückt hatten ${ }^{43}$. Paris bildete dabei keine Ausnahme. $\mathrm{Zu} \mathrm{Zu}$ sammenstößen zwischen katholischen Anhängern Jeannes und der Linken kam es etwa genauso in Lille ${ }^{44}$ und selbst in Orléans als der Hochburg des Kults ${ }^{45}$.

Spätestens nach der Jahrhundertwende schaltete sich auch der extrem rechte französische Nationalismus in den Disput um die Jeanne-Figur ein. Als symptomatisch erwies sich in dieser Hinsicht, daß der Führer der rechten Ligue des Patriotes Paul Déroulède zu den Ehrengästen der Feierlichkeiten in Orléans zählte, wo er Jeanne d'Arc als Inbegriff der »France« und als "patriote chrétienne « würdigte ${ }^{46}$. Er nutzte hier geschickt die Ressentiments der Republik gegenüber dem religiösen Kult, um sich dem französischen Katholizismus zur Allianz der Kräfte eines rechten Frankreich anzubieten. Bereits anläßlich des Nationalfeiertags 1900 hatten nationalistische Gruppen neben der Statue de Strasbourg auf der Place de la Concorde auch die Jeanne-Statue auf der

39 Vgl. Le Constitutionnel, 11. Mai 1907, S. 3.

40 Vgl. ibid. 16. Mai 1909, S. 2.

41 Vgl. Le Petit Joumal. 17. Mai 1909, S. If.

42 Le Petit Joumal skizzierte ein extrem breites Sozialprofil der Demonstranten, zu denen ein Industrieller ebenso zählte wie diverse Händler, ein Buchdrucker, ein Schneider, ein Student und drei Arbeitslose.

43 Vgl. Le Petit Journal, 17. Mai 1909, S. 2.

44 Vgl. ibid. 10. Mai 1909, S. 3.

45 Vgl. ibid. 9. Mai 1909, S. 2; vgl. auch GIDEA, The Past in French History, S. 157161. Zum frühen Kult in Orléans [An.,] Souscription nationale déstinée à ériger une statue à Jeanne d'Arc, Orléans 1848; vgl. auch PROST, Jeanne à la fête, passim; Nora $\mathrm{H}$. HEIMANN, The art of politics in early nineteenth century France: E.E.F. Gois's "Jeanne d'Arc pendant le combat $\ll$ as metaphor, in: GBA 140 (1998) S. 29-46.

46 Vgl. Le Petit Journal, 9. Mai 1909, S. 2. Vgl. Martha HANNA, Iconology and ideology: Images of Joan of Arc in the Idiom of the Action Française, 1908-1931, in: FrenchHSt 14 (1985/86), S. 215-239. 
Place des Pyramides in einen "pèlerinage national« mit Kranzniederlegungen einbezogen ${ }^{47}$. Noch während des Ersten Weltkrieges hielt die Ligue des patriotes an entsprechenden Riten im Mai jeden Jahres fest und bezog etwa 1917 sogar alle drei Jeanne-Statuen mit ein, legte aber am Denkmal auf der Place des Pyramides nicht anders als etwa die populistisch-radikale Action françai$\mathrm{se}^{48}$ einen Kranz nieder ${ }^{49}$. In dergleichen Anläufen zur symbolischen und programmatischen Inbesitznahme des ersten und zentralsten der Pariser JeanneMonumente schlug sich die Anwartschaft der rechtsextremen Kräfte auf neue Deutungshoheiten im Jeanne-Kult nieder. Man zielte hier auf ein fundamental antirepublikanisch-reaktionäres Bekenntnis zu »Armée« und Krieg und setzte sich damit mit eigenen Akzenten über den jahrzehntealten, an der religiösen und ordnungspolitischen Binnenkonstituierung der Nation orientierten Disput hinweg. Die zahlreichen öffentlichen Zwischenfälle, die sich entweder in direkter Nähe eines der Pariser Monumente abspielten oder aber zumindest das weiße Banner der Jeanne d'Arc exponierten, zeugen davon, daß der Versuch einer letztgültigen Übernahme der Pucelle in den personalen Kultvorrat der Republik bis 1914 nicht vollends gelang.

\subsection{Voltaire zwischen laizistischem Messianismus und katholischer Apostasie}

Paris kam nach jahrelangem öffentlichen Disput Mitte und Ende der 1880er Jahre gleich zu zwei Voltaire-Denkmälern. Tatsächlich verdankte sich diese Häufung weniger einem generösen Kult, als vielmehr verbissenen rhetorischprogrammatischen Grabenkämpfen um das konfessionelle bzw. säkulare Werteprofil der Nation zum einen und um das traditionsstiftende Potential der Revolution von 1789 zum anderen.

Die Umstrittenheit Voltaires, die sich im Kontext einer Denkmalerrichtung in Paris 1885 auf dem Quai Malaquais bemerkbar machen sollte, war spätestens 1867 zutage getreten, als der republikanisch-oppositionelle Siècle eine Subskription für ein Voltaire-Denkmal in die Wege zu leiten versuchte ${ }^{50}$. Das Denkmalprojekt war Teil der republikanischen Strategie, gegenüber den offiziellen stärker eigene Traditionen des Empire geltend zu machen und dazu selbstbewußt den öffentlichen Raum zu suchen, um hier den Symbolkampf mit den Herrschaftszeichen der Monarchie und des Militarismus aufzunehmen:

${ }^{47}$ Vgl. La Croix, 16. Juli 1900, S. 4.

48 Vgl. zur Action française hier nur STERNHELL, La droite révolutionnaire, S. 348- 401.

${ }^{49}$ Vgl. Le Temps, 21. Mai 1917, S. 3.

so Vgl. Le Siècle, 25. Januar 1867, zit. nach HARGrove, Les statues de Paris, La représentation, S. 102 mit Anm. 25; J. VERCRUYSSE, C'est la faute à Rousseau, c'est la faute à Voltaire, in: Studies on Voltaire in the eighteenth century 23 (1963) S. 61-76. 
Il est temps que dans un pays comme le nôtre, dans une société qui se prétend démocratique, on honore enfin, à la face de tous, les hommes qui ont servi la cause du progrès, de la civilisation, de l'humanité, les seuls que nous devions finalement glorifier; bienfaiteurs avec lesquels ne rivalisent pas, non-seulement les généraux habiles dans l'art de conduire sur le champ de campagne les troupes disciplinées, mais encore les chefs d'État, les souverains ${ }^{51}$.

Die Monumentalisierung Voltaires war - auch als Rekurs auf eine bereits während der Revolution von 1789 etablierte Kultpraxis ${ }^{52}$ - als Bekenntnis zum politischen wie säkularen Antitraditionalismus gedacht. Darüber hinaus hatte sie eine dezidiert antinapoleonische StoBrichtung, zielte auf einen Gegenentwurf zur Napoleon-Figur auf der Vendômesäule, in der sie nicht die Siege, sondern die Niederlagen Frankreichs verkörpert sah $^{53}$. Voltaire avancierte so zum historischen Kronzeugen für das republikanische Regime, das auf Ablösung des autoritären Systems drängte ${ }^{54}$.

Dem Aufruf im Siècle folgte ein Sturm konservativer und katholischer Entrüstung. Wortreich wurde aus seinem Euvre zitiert, um authentische Gegenbelege beizubringen, die Voltaire wegen politischer, religiöser und moralischer Inkompetenz als Repräsentanten der Nation obsolet machen sollten ${ }^{55}$. Maurice Leprévost apostrophierte ihn als »mauvais citoyen « und »hypocrite ${ }^{56}$, der Frankreich gegenüber Friedrich dem Großen lächerlich gemacht und die Kirche und ihre Dogmen diskreditiert habe. Krudes Preußentum als Indiz für nationale Unzuverlässigkeit und blasphemischer Sarkasmus als Reflex eines verbitterten Atheismus, in diesen Vorwürfen gipfelten regelmäßig die konservativen Attacken gegen die republikanische Voltaire-Figur.

Als personale Antithese erschien in der konservativen Voltaire-Kritik Jeanne d'Arc, deren Andenken in seinen Schriften desavouiert zu haben Voltaire den schwersten Vorwurf der »lèse-nation«, des »attentat à l'honneur national« eintrug $^{57}$. Angesichts der Denkmalpläne meldeten sich Verfechter eines Nationalismus zu Wort, die das Recht auf eine zutiefst religiös konnotierte nationale Identität aggresiv einklagten ${ }^{58}$. Dem Chefredakteur des Siècle Léonor Havin warf man die modernistisch-aufklärerische Verführung zu sincrédulité« und

51 Ch. D'HENRIET, La statue de Voltaire, in: La Philosophie positive 2 (janvier-juin 1868), S. 367-385, hier S. 383.

52 Zum Voltaire-Kult vgl. Robert L. HERBERT, David, Voltaire, Brutus and the French Revolution: an essay in art and politics, London 1972, S. 68-71, 81-86.

53 D'HENRIET, La statue de Voltaire, S. 384.

54 Vgl. C. POIRÉE, Une statue à Voltaire? o. 0. 1867, S. 11.

${ }^{55}$ Vgl. u.a. [An.,] La statue de Voltaire, érigée par lui-même, Paris 1867, S. 7, 8, 16 und passim.

56 Maurice LePrévost [i.e. Maurice MAIGNEN], La statue de Voltaire, Périgieux 1867, S. 12.

57 Vgl. ibid. S. 19: „Non! pas de statue à Paris pour Voltaire! Pas de statue sur la terre de France au blasphémateur de Jeanne d'Arc! « Vgl. ähnlich [P. FRETTÉ,] La statue de Voltaire. Qui la paiera? Songe d'une nuit d'été dédié à M. de St. ${ }^{\circ}$ Beuve, Paris 1868, S. 9.

58 LEPRÉVOST, La statue de Voltaire, S. 31 [H. i. O.]. 
»libertinage $\ll$ vor $^{59}$ und konterte mit einem konservativ-konfessionellem Bekenntnis: »Mais la France restera fidèle à ses immortelles et catholiques traditions; (...), la France catholique sera toujours noble, grande et généreuse $\aleph^{60}$. Selbst in der späten, von Liberalisierungseffekten gelockerten politischen Atmosphäre des ausgehenden Zweiten Empire blieb angesichts eines etablierten, wenn auch inzwischen autoritär gezähmten Klerikalismus für eine säkularer konnotierte Voltaire-Figur kein Raum.

Mit dem Zusammenbruch des Empire und der Neugründung der Dritten Republik vollzog sich zwar faktisch ein strategischer Rollentausch, der die republikanischen Voltaire-Adepten nun begünstigte; Symbolmacht erhielten sie indessen keineswegs automatisch, sondern erst mit Verzögerungen. Die Kontroverse um den nationalen Kultstatus Voltaires wurde 1878 neu entfacht, als die Frage einer Hundertjahrfeier am 30. Mai 1878 öffentlich und unter großer Anteilnahme der Presse diskutiert wurde ${ }^{61}$. Bereits seit 1876 propagierte die laizistisch-republikanische Ligue des Droits de l'Homme die Idee, einen Centenaire für Voltaire mit der Weltausstellung 1878 zu verbinden ${ }^{62}$. Der Pariser Stadtrat unterstützte das Projekt mit einem programmatischen Bekenntnis zum "précurseur de la Révolution française «" ${ }^{63}$. Das republikanische Votum für Voltaire wies verglichen mit der in der Spätphase des Empire vertretenen Version Modifikationen auf. Es zielte nicht mehr nur auf die legitimatorische Emanzipation der Republik von der Monarchie, es dokumentierte vor allem, daß das republikanische Frankreich nach der inzwischen erfolgten Etablierung der Dritten Republik große, traditionsreiche Sinnstifter benötigte. Voltaire wurde weniger pointiert für die demokratische Republik, aber umso stärker für die Reaktivierung des revolutionären Erbes von 1789 in Beschlag genommen.

Victor Hugo schließlich steigerte den Kult zu einer Art säkularer Apotheose: Voltaire erschien in seinem Kampf gegen Traditionalismen, Dogmen und despotische Autoritäten als erster Nachfolger Christi, dessen Evangelium freilich jeder Metaphysik beraubt und auf ein revolutionäres Kampfprogramm gegen Unterdrückung, Entrechtung und Tyrannei reduziert worden war ${ }^{64}$. So avancierte Voltaire zum republikanischen Messias, der Frankreich das Evangelium der Aufklärung und der Revolution zu bringen hatte. Zugleich versöhnte er die Dritte Republik mit dem Ancien Régime, indem er das 18. Jahrhundert als

Ibid. S. 9, 14

Vgl. GOULEMOT, WALTER, Les centenaires de Voltaire et de Rousseau, passim.

Vgl. Félix-Antoine-Philibert DUPANLOUP, Premières lettres à MM. les membres du Conseil Municipal de Paris sur le Centenaire de Voltaire, Paris 1878, S. 5f.; Propositions et projets de vœux, séance du 23 février 1878, in: CMPV, Année 1878, S. 68.

63 Subvention (...), séance du 7 mars 1878, in: CMPV, Année 1878, S. 122f., hier S. 122.

${ }^{64} \mathrm{Vgl}$. Petit Journal, 1. Juni 1878, S. 1-2, hier S. 2. Vgl. auch GoulEMOT, WALTER, Les centenaires de Voltaire et de Rousseau, S. 403, 406. 
philosophisch ergiebiges "siècle de Voltaire ${ }^{65}$ in die Nationalgeschichte Frankreichs zu absorbieren erlaubte. Damit konnte über die Voltaire-Figur jene Kontinuitätsstiftung gelingen, aus der die Dritte Republik legitimatorische Kraft zu schöpfen suchte: von der Aufklärung über die Revolution bis zur neuen Republik der 1870er Jahre, die in der Vision Hugos diese Epochen in einer Phase des "progrès« und der "paix« zu ihrer glorreichen Synthese brachte ${ }^{66}$. Die nationale Geschichte Frankreichs mündete dann schon fast teleologisch in die Dritte Republik und Voltaire war der Garant und Begründer dieser Entwicklung ${ }^{67}$.

Die konservative und katholische Kritik fiel heftig aus ${ }^{68}$. Der Bischof von Orléans, Mgr. Dupanloup, der für einen gleichermaßen populären wie kirchlich domestizierten Heiligenkult der Jeanne d'Arc kämpfte und sich von der erstrebten Kanonisierung der Pucelle einen regelrechten Missionierungs- und Popularitätsschub zugunsten der gallikanischen Amtskirche erhoffte, versuchte vergeblich, Rechtsmittel gegen die zahlreichen Neuauflagen Voltairescher Werkauszüge einzulegen, die breite Passagen mit sarkastischen Einlassungen zur christlichen Religion enthielten ${ }^{69}$. Bis das Denkmal 1885 Gestalt annahm, waren die argumentativen Fronten im öffentlichen Diskurs also längst festgefahren.

Nachdem ihnen in der Frühphase der Republik zunächst noch ein konsenswilliger Republikanismus den Affront gegen den katholischen Konservativismus untersagt hatte ${ }^{70}$, gewannen die Voltaire-Apologeten unter den Bedingungen einer vielfach polarisierten politischen Kultur der Dritten Republik schließlich die Oberhand, so daß am 14. Juli 1885 das Denkmal für Voltaire auf dem Quai Malaquais tatsächlich eingeweiht werden konnte. Das ohne Zwischenfälle absolvierte und von durchaus renommiertem politischen Personal $^{71}$ verfolgte Prozedere sprach für einen klaren Deutungserfolg des republikanischen Voltaire-Kults. In der Tat feierten Redner wie der radikale Journalist Guyot das Denkmal als öffentliches Triumphfanal ${ }^{72}$ und schöpften noch

${ }^{65}$ Ibid. Die Stilisierung des »gouvernement sans Dieu ni roik stand unmittelbar nach den Voltaire-Feiern bei der öffentlichen Inszenierung eines Denkmals für den Positivisten und Fortschrittsphilosophen Auguste Comte im Mai 1902 im Mittelpunkt. Vgl. Le Temps, 19. Mai 1902, S. 3 und Comité international de la statue d'Auguste Comte, Paris o. J. Vgl. Petit Journal, 1. Juni 1878, S. 2

67 Vgl. dazu die konservative Kritik in Le Monde, 31. Mai 1878, S. 1

${ }^{68}$ Vgl. so das Votum des Comité catholique de Lille nach dem Bericht in Le Temps, 17. Mai 1878, S. 2.

${ }^{69}$ Vgl. Le Petit Journal, 24. Mai 1878, S. 1; Le Temps, ibid. 19. Mai 1878, S. 2.

${ }^{70} \mathrm{Vgl}$. zum staatlichen Verbot öffentlicher Voltaire-Feiem 1878 bereits Kapitel V.1.1.

7 Vertreten waren u.a. der Präsident der Abgeordnetenkammer Floquet, der Präsident der Société des gens de lettres Arsène Houssaye, Seinepräfekt Poubelle und der Republikaner Spuller. Vgl. Le Petit Journal, 16. Juli 1885, S. 2; Le Temps, 15./16. Juli 1885, S. 2; Le Radical, 16. Juli 1885, S. 2.

72 Vgl. ibid. 
einmal reichlich aus dem Arsenal der Voltaire-Panegyrik ${ }^{73}$. Der Präsident des Conseil Municipal Michelin schließlich machte kämpferisch geltend, daß die Regierung nun bald für die Überführung der sterblichen Überreste Voltaires ins Pantheon Sorge tragen und damit die Initiative zu einem Ende bringen solle, die die Assemblée constituante bereits am 30. Mai 1791 auf den Weg gebracht hatte ${ }^{74}$. Die Polemik der konservativen Blätter gegen das Denkmal als den Vorboten einer erzwungenen Säkularisierung ${ }^{75}$ nahm sich wenig originell aus. Neu war hingegen, daß man sie auf den republikanischen Nationalfeiertag ausweitete, auf den das Denkmalfest symbolträchtig gelegt worden war, und dessen Verbindlichkeit nun erbittert bestritten wurde ${ }^{76}$. Damit dominierten im Diskurs von den ersten Initiativen während des ausgehenden Empire bis zur Mitte der 1880er Jahre weitgehend starre Deutungsmuster. Argumentative Vermittlungsspielräume, wie sie sich im Toleranzappell des Temps $^{77}$ auftaten, blieben ungenutzt.

Der Höhepunkt des aufgeregten Voltaire-Diskurses war fast schon überwunden, als es im November 1887 zur Errichtung eines weiteren Voltaire-Denkmals im semioffiziellen Raum, nämlich dem Innenhof der Mairie des 9. Arrondissement, kam. Die Feier stand allerdings unter deutlich munizipalen Vorzeichen ${ }^{78}$, indem Conseiller Daumas seine Festrede zum Plädoyer für mehr wautonomie communale « nutzte, dabei aber durchaus auf den Unmut seiner Zuhörerschaft stieß, die einer von der nationalen Relevanz Voltaires absehenden Deutung des Denkmals zugunsten kommunalpolitischer Belange der Kapitale nicht folgen mochte. Die Unstimmigkeiten konnten schließlich notdürftig mit den Klängen der Marseillaise überdeckt werden ${ }^{79}$. War schon im Vorfeld die Voltaire-Figur von ihren Stiftern nicht nur mit areligiösen Postulaten, sondern auch mit Demokratie- und Egalitätsidealen assoziiert worden, zeugte das zweite Denkmalprojekt nun einmal mehr von der konnotativen Großzügigkeit, mit der der Emanzipationsgedanke, für den Voltaire stand, nach Bedarf nun auch auf die der Figur sonst gänzlich fremde munizipale Autonomiede-

3 Vgl. [V. SARDOU,] Inauguration de la statue de Voltaire le mardi 14 juillet 1885 . Discours de M. V.S., directeur de l'Académie Paris 1885 (Institut de France. Académie Française), S. 4.

74 Vgl. ibid.

75 Vgl. La Croix, 16. Juli 1885, S. 1; ibid. 18. Juli 1885, S. 1; Le Monde, 15. Juli 1885, S. 1-2 [Oscar HAVARD]; ibid. 16. Juli 1885, S. 1; L'Univers, 17. Juli 1885, S. 1.

76 La Croix, 15. Juli 1885, S. 1; Le Monde, 16. Juli 1885, S. 1 [O. HAVARD] und ibid. [A DEVILLE].

7 Vgl. Le Temps, 15./16.Juli 1885, S. 1 .

78 Geladen waren Senatspräsident Le Royer, zwei Mitglieder des Conseil und der Bürgermeister des 9. Arrondissements Emile Ferry. Vgl. Le Temps, 8. November 1887, S. 3.

79 Vgl. Ernest DUPRÉ, Voltaire à vingt-cinq ans, in: L'Artiste, Dezember 1887, S. 409-415, hier S. 414-415; Le Temps, 8. November 1887, S. 3; L'Univers, 10. November 1887, S. 1 [Auguste RoussEL]; La Croix, 9. November 1887, S. 1; [An.,] La statue d Voltaire, Paris o. J. 
batte ausgeweitet werden konnte. An dieser Stelle wurden manipulative Techniken zeitgenössischer Sinnzuweisung an die öffentlichen Monumente erkennbar, die zum Verfahren nationaler Bedeutungsprojektionen gehörten. Der Voltaire-Kult offenbarte jedenfalls im Rahmen beider Monumentalisierungen und ihrer diskussionsreichen Vorbereitungsphase eher Sollbruchstellen und Fraktionierungen von Nationskonzepten statt diskursive Verbindlichkeiten.

\subsection{Symbolduelle und-repliken: Katholizismus, Laizismus, Protestantismus und Nation}

Seit Ende der 1880er Jahre erwies sich mit Étienne Dolet und Chevalier de la Barre historisches Personal aus dem konfessionellen 16. und 17. Jahrhundert als geeignet, einer Exklusion des Katholizismus aus der säkular definierten Nation monumental und programmatisch nachgerade militant Ausdruck zu verleihen. Immerhin gelang aber dem Katholizismus in Paris - fundamental anders als in Berlin und provokanter als in London - zumindest nach der Jahrhundertwende durchaus die monumentale Replik in Gestalt eines ServetDenkmals. Etwas außerhalb des monumentalen Schlagabtauschs blieb der Versuch einer nationalen Selbstverortung des Protestantismus im nationalen Gefüge anhand einer öffentlichen Coligny-Figur.

Im Mai 1889 wurde zunächst ein Denkmal für den freidenkerischen Häretiker des 16. Jahrhunderts Étienne Dolet auf der Place Maubert am Boulevard Saint-Germain im Seine-nahen Norden des 5. Arrondissements eingeweiht. Den Deutungstenor des Projekts lieferten bereits seine frühen Initiatoren: Der Arbeiter Steckle, der 1881 die erste Petition an den Conseil richtete, hatte die Statue bereits für den "savant humaniste, imprimeur, poète et grammairien (...) que l'on brûla vif (...) place Maubert, le 3 août 1546, à 37 ans $\varkappa^{80}$ gefordert; später auch für »un des génies les plus purs de la nation française ${ }^{81}$. In seiner Antwort präzisierte der Seinepräfekt das geplante Denkmal als eine Würdigung des "victime de l'intolérance (...) qui fut un des plus énergiques représentants de la renaissance intellectuelle en France « ${ }^{82}$. Über notorische Bekanntheit schien die Figur freilich aus zeitgenössischer Sicht nicht zu verfügen, denn Conseiller Léon Delhomme, der die Initiative 1884 wieder aufgriff und dem Conseil anempfahl, erachtete es durchaus für notwendig, wenigstens kursorisch über die historische Person zu informieren, indem er Lexikonpassa-

${ }^{80}$ Steckle an den Conseilpräsidenten Herold am 25. September 1881, zit. nach Le Temps, 19. Mai 1889, S. 2.

${ }^{81}$ Vgl. Rapport, in: CMRD, Année 1884, Imp. $N^{\circ} 40$, S. 3. Zum Dolet-Denkmal in Lyon vgl. COHEN, Symbols of power, S. 502.

${ }^{82}$ Schreiben des Préfet de la Seine Herold vom 16. November 1884 an den Conseil, zit. nach Rapport, s.o., S. 2. 
gen paraphrasierte, die Dolet als Gegner des Katholizismus identifizierten, den die Kirche darum der Inquisition überantwortet hatte ${ }^{83}$. Darüber hinaus fand am Vorabend der Denkmaleinweihung im Festsaal des 5. Arrondissements eigens eine vom Abgeordneten Désiré Bourneville geleitete Konferenz über Leben und Werk Dolets statt, die Anlaß bot, die Programmatik der Denkmalstifter beredt $\mathrm{zu}$ entfalten ${ }^{84}$. Bournevilles Dolet verkörperte die Parteinahme "contre le cléricalisme« und stand für die Forderung nach egalitärer und laizistischer Bildung als Ideal der areligiösen Nation ${ }^{85}$. Dabei konnte Bourneville sich an einen traditionsreichen Diskurs anlehnen, denn bereits zur Zeit des Empire war Dolet mitunter als unerbittlicher Gegner eines mystischen Katholizismus gefeiert worden ${ }^{86}$.

Bereits der Einweihungstermin wenige Tage nach der Eröffnung der Weltausstellung und im Rahmen einer ganzen Serie nationaler Festivitäten im Jahr des Centenaire der Revolution von 1789 verlieh dem Denkmalfest eine spezifisch republikanische Note. Die Geladenen sowie verschiedene Vereine zogen zunächst vom Hôtel de Ville zur Place Maubert, wo sie das Denkmal unter den Klängen der Marseillaise enthüllten. In den vor allem von Vertretern der Libre Pensée gehaltenen Reden räsonierte man über die Säkularisierungsleistung der Revolution von 1789, zu deren frühneuzeitlicher Avantgarde Dolet jetzt erklärtermaßen zu rechnen war $^{87}$. Schließlich endete das Zeremoniell mit einem Defilee des Festzuges, der mit Bannern salutierend an dem Denkmal vorüberzog. Um auch in zeremonieller Hinsicht das Deutungsmonopol zu reklamieren, lud im Anschluß an die Einweihung die Libre-Pensée des Arrondissements die Mitwirkenden zu einer gemeinsamen Veranstaltung ${ }^{88}$.

Die Monumentalisierung Dolets provozierte zu heftigem Widerspruch und zur Zurückweisung des Fanatismusverdikts gegen die katholische Kirche, die selbst in Form monographischer Darstellungen erfolgte ${ }^{89}$. Zur programmatischen Widerrede kam der Hinweis auf den Spaltungseffekt in der nationalen Gesellschaft, den die Statue als »obstacle à l'union« zu zeitigen drohe ${ }^{90}$. Das

${ }^{83}$ Vgl. Rapport, ibid. S. 4.

${ }^{84}$ BOURNEVLLE, Étienne Dolet. Sa vie, ses oeuvres, son martyre. Conférence faite le $18 \mathrm{mai}$ 1889 à la mairie du $V^{e}$ artondissement à l'occasion de l'inauguration de la statue d'Étienne Dolet sur la place Maubert, Paris 1889 (Société de la Libre Pensée du $\mathrm{V}^{e}$ arrondissement, Groupe Étienne Dolet), S. 3-7.

85 Ibid. S. 35

${ }^{86}$ Vgl. Joseph BoUlmier, Estienne Dolet. Sa vie, ses oeuvres, son martyre, Paris 1857, S. 256-267.

${ }^{87}$ Le Temps, 20. Mai 1889, S. 1.

88 Vgl. ibid.

89 Vgl. L'abbé DANIEL [vicaire à Saint Nicholas du Chardonnet, dit Louis Michel], Dolet, sa statue place Maubert. Ses amis, ses ennemis, Paris 1889, S. 3.

90 Vgl. ibid. S. 16 und 23. Vgl. ähnlich Jean DE LA NIVE, Étienne Dolet. Soi-disant librepenseur, soit-disant brûlé vif, auquel le Conseil Municipal de Paris élève une statue place Maubert aux frais des contribuables, Bourges 1889, S. 1-3 und passim. 
monumentale Zeichen erachteten seine Kritiker als Teil eines aggressiven Bilddiskurses, einer öffentlichen Brüskierungsstrategie, die auf Differenz und Abgrenzung, nicht aber auf Inklusion zielte ${ }^{91}$.

Während die Rhetorik im Umfeld des Dolet-Denkmals ähnlich wie im Rahmen der Voltaire-Initiativen erneut die Kompatibilität von republikanischsäkularer Nation und Katholizismus zum Gegenstand hatte, erhob nun Ende der 1880er Jahre erstmals ausdrücklich der Protestantismus mit einem Coligny-Denkmal den Anspruch, mit dem Bekenntnis zur französischen Nation vereinbar zu sein. Wenige Tage nach dem Nationalfeiertag, am 17. Juli 1889, erhielt Gaspard de Coligny eine Statue an der Rue de Rivoli an der Chorseite des Temple de l'Oratoire, wo er im Zuge der Bartholomäusnacht im August 1572 als politischer Anführer und militärischer Kopf der protestantischen Partei auf der Seite der Bourbonen und des Prinzen Condé im Religionskrieg ermordet worden war ${ }^{92}$. Die Einweihungsfeier, auch sie im Centenaire-Jahr von republikanisch-nationaler Symbolik bestimmt, aber weniger unvermittelt öffentlich, wurde im protestantischen Oratoire abgehalten, das zu diesem Zweck mit zahlreichen Trikoloren ausstaffiert, allerdings wie die Ehrungen ähnlich kategorisierbaren Personals nicht von Vertretern der Regierung frequentiert war $^{93}$. In den öffentlichen Raum begab sich die Festgesellschaft erst, als sie in den am Oratoire gelegenen Garten zog und dort am Denkmal vorbeidefilierte ${ }^{94}$.

Komiteepräsident Graf Jean François de Jaucourt wertete die Mitwirkung von Katholiken im Komitee ausdrücklich als Zeichen dafür, daß hier kein monumentaler wacte de parti religieux" vollzogen werden sollte, sondern die Ehrung Colignys ausschließlich um der "gloire du pays« willen erfolgte ${ }^{95}$. Dem protestantischen Geistlichen Eugène Bersier zufolge evozierte der Anblick Colignys vor allem den Zustand der im Religionskrieg extrem dissoziierten Nation, der "pauvre France ravagée«, in der sich nicht nur religiöse Feinde, sondern auch politische und private Fehdeführer gegenübergestanden und das Land bis in seine kommunalen Gemeinschaften hinein zu zersprengen gedroht hatten. In dieser Situation ließ Bersier Coligny als militärischen Patrioten und religiöses, aber konfessionell neutrales Gewissen Frankreichs auftreten, der auf einen befriedeten »ordre intérieur« zielte. Bersier leugnete nicht notwendig

91 Vgl. DANIEL, Dolet, S. 23.

92 Vgl. auch zum folgenden Le Temps, 18. Juli 1889, S. 3.

93 Vgl. ibid. Der Zeremonie folgten Komiteepräsident Jaucourt, der Directeur des Beaux-Arts Gustave Larroumet, der Vizepräsident des Conseil Municipal Richard, der Präsident des Konsistoriums der Église réformée de Paris, ein Pfarrer sowie zwei Senatoren und mehrere Mitglieder des Komitees.

94 Vgl. ibid.

95 Vgl. Le MARQUIS DE JAUCOURT, Eugène BERSIER (Hg.), Discours prononcés le mercredi 17 juillet 1889 pour l'inauguration du monument de l'Amiral Coligny, Paris 1889, S. 913. 
konfessionelle Konfliktlinien in der Gesellschaft des modernen Frankreich, betonte aber die Chance, die in einer gewandelten Streitkultur lag, indem in der »France moderne« des ausgehenden 19. Jahrhunderts keine "guerres religieuses « mehr, sondern maximal noch gewaltlos-diskursive »luttes fécondes et nécessaires de la pensée et de la charité» ausgetragen wurden. Von hier aus konnte die Rede in einem Plädoyer für die inklusive und egalitäre Nation gipfeln, die weder konfessionell noch sozial exklusiv verfuhr, sondern dem "plébéien, bourgeois« oder "gentilhomme« offen stand ${ }^{96}$.

Den Konsensformeln zum Trotz war bereits in einer frühen Phase der Initiative Kritik laut geworden. Coligny erschien als Begünstiger des Mordkomplotts gegen den katholischen Herzog von Guise 1563 und als Provokateur der "guerre civile«, mit der die gewaltsame Inbesitznahme Frankreichs durch den Protestantismus erzwungen werden sollte ${ }^{97}$. Demgegenüber wurde die fundamentale Verankerung der "société française« im Katholizismus als der »âme de la famille, de la cité, de la nation « beschworen und der Protestantismus als wétranger« und der französischen Nation genuin fremde Konfession bezeichnet $^{98}$. Zwar wies ein Bulletin des protestantischen Geschichtsvereins die Vorwürfe energisch zurück ${ }^{99}$; und doch hielt der Widerspruch auch nach der Denkmaleinweihung 1889 an. So optierte Le Monde zum einen an der Seite von Colignys Gegnern im 16. wie im 19. Jahrhundert für die zentralistische "unité politique de la France» und sah zum anderen die wnationalité« Frankreichs pathetisch durch das Blut der Jeanne d'Arc auf den Katholizismus festgelegt, bot also die katholische Nationalheilige auf, um die Kombination von Nation und Protestantismus zu delegitimieren ${ }^{100}$. Die Denkmalinitiatoren und ihre Sympathisanten ließen diese Anschuldigungen nicht auf sich beruhen ${ }^{101}$. Damit setzte sich der Disput aber nur erneut fort, während Konsensformeln nicht gefunden wurden.

Mit der Denkmaleinweihung hatte sich dessenungeachtet der französische Protestantismus erstmals selbstbewußt in den monumentalen Diskurs in der Hauptstadt und den Symbolstreit um die religiöse und konfessionelle Identität der französischen Nation öffentlich eingeschaltet. Die symbolische Involvierung wirkte bescheiden, entsprach damit aber durchaus seiner minoritären Position in der französischen Gesamtgesellschaft, an der auch die Beteiligung

96 Ibid.

97 Ch. BARTÉLÉMY, Erreurs et mensonges, Bd. 15, Paris o. J., S. 230-245.

98 Vgl. ibid. S. 235-236.

99 Vgl. Bulletin historique et littéraire de la Société de l'histoire du protestantisme Français 32 (1883), S. 95f.

${ }^{100}$ Vgl. Le Monde, 19. Juli 1889, S. I [Oscar HAVARD]; La Croix, 19. Juli 1889, S. 1-2, hier S. 1 .

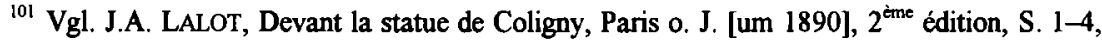
69. 
von Protestanten an der Regierung in der fortgeschrittenen Jahrhunderthälfte nichts geändert hatte.

Nachdem genau zur Jahrhundertwende der republikanischen Ligue Française de l'Enseignement mit der Denkmalsetzung für ihren Gründer Jean Macé im 19. Arrondissement die Ergänzung des Symbolareals um einen renommierten Vertreter laizistischer Nations-Bildung gelungen war $^{102}$, setzte sich der dezidiert antiklerikale Disput fort. Dies geschah zunächst mit dem Anfang November 1906 für das legendäre Inquisitionsopfer Chevalier de la Barre in der Rue Lamarck im nördlichen 18. Arrondissement (Montmartre) entstandenen Denkmal. Dort stand es - sichtlich konstitutiver Teil von Programmatik und symbolischer Dramaturgie - provokant nahe am zentralen und pompösen Kultort des Katholizismus Sacré-Cœur, dem Relikt einer populären Frömmigkeitsbewegung nach dem Krieg 1871 und einer ursprünglich royalistischkatholischen Mehrheit in der Assemblée Nationale in der frühen Phase der Republik $^{103}$, das seit der Beteiligung der antiklerikalen Radikalen an der Regierung nach der Jahrhundertwende permanenter Anfeindung ausgesetzt war $^{104}$.

Der Monumentalisierung ging eine lange Legendenbildung um die Figur voraus. Bereits Voltaire hatte den Fall des jungen Offiziers exemplarisch verhandelt, und die Voltaire-Feierlichkeiten 1878 gaben mehrfach Anlaß dazu, den historischen Präzedenzfall erneut aufzugreifen. In diesem Rahmen hatte Hugo die Legendenvariante Voltaires übernommen, nach der der Offizier de la Barre [d.i. Jean-François Lefebvre] 1765 in Abbeville bezichtigt worden war, ein auf dem Pont d'Abbeville stehendes Kruzifix gestürzt zu haben. Unschuldsbeteuerungen konnten den gerade neunzehnjährigen Angeklagten am Ende nicht vor Inhaftierung, qualvoller Folter und dem öffentlichen Flammentod bewahren ${ }^{105}$. Die Legende vom Chevalier de la Barre als Opfer eines

${ }^{102}$ Die Statue befand sich auf der Place Armand-Carel zwischen dem Bürgermeisteramt des 19. Arrondissements und dem Parc des Buttes-Chaumont im Nordosten der Stadt. Vgl. Le Temps, 14. Juli 1900, S. 2; La Petite République, 15. Juli 1900, S. 1; [An.,] Inauguration du monument élevé à la mémoire de Jean Macé et à la glorification de l'enseignement laïque, le vendredi 13 juillet 1900 , Paris 1900.

${ }^{103} \mathrm{Vgl}$. LOYER, Le Sacré-Cœur de Montmartre, passim; Raymond A. JONAS, Monument as Ex-Voto, Monument as Historiography: The Basilica of Sacré-Cœur, in: FrenchHSt 18 (1993) S. 482-502.

${ }^{104}$ Vgl. Ibid. S. 460.

${ }^{105}$ Vgl. [Victor HUGO,] Lettres de mon curé ( $1^{\text {er }}$ lettre). Les processions par Un Ami de la Liberté; suivi de l'Histoire du Supplice de Jean Calas et du supplice du Chevalier de la Barre, o. O. o. J. [1895], S. 13-17. Vgl. auch GILDEA, The Past in french History, S. 219; Eric WALTER, L'affaire La Barre et le concept d'opinion publique, in: Centre d'Etudes du XVIIle siècle de l'Université Lyon III (Hg.), Le journalisme d'Ancien Régime. Questions et propositions. Table ronde CNRS 12-13 juin 1981, Lyon 1982, S. 361-392. 
indoktrinären Katholizismus blieb weiter publizistisch präsent ${ }^{106}$ und umstrit$\operatorname{ten}^{107}$.

An der Einweihungszeremonie am sonntäglichen Nachmittag des 4. November 1906 schließlich nahmen neben der von Intellektuellen und Protestanten geprägten Ligue des droits de l'homme und Sektionen des Parti socialiste mehrere Gruppen der eher populär und radikal dominierten Libre-Pensée teil ${ }^{108}$. Im Anschluß an die feierlichen Ansprachen zogen mit den verschiedenen Sociétés am Ende etwa 2.000 Personen um das Denkmal, und am Abend des gleichen Tages fand ein Bankett in der Avenue Clichy statt ${ }^{109}$. Die offizielle Republik vermied es, sich direkt in die zur Laizismuskampagne umfunktionierte Denkmaleinweihung involvieren zu lassen, ohne umgekehrt die Manifestation zu unterbinden. Nur für die Stadt Paris bekundeten mehrere Conseillers als Teilnehmer oder Redner ihre Sympathie ${ }^{110}$. Die Genugtuung über die Symbolkonfrontation schlug mitunter in eine Kampfansage um das noch verfügbare Symbolterrain in der Hauptstadt um, indem prognostiziert wurde, da $B$ der "première victoire« weitere folgen würden, bis die laizistischen Denkmalstifter als "maîtres incontestés de la place« daständen ${ }^{111}$. Daß die antikirchliche Symbolhoheit optimal erst mit der »disparition du Sacré-Cœur « zu verwirklichen sei, bot schließlich sogar Anlaß, offen den Sturz des katholischen Baudenkmals als letzten Schritt zu einem totalen republikanisch-laizistischen Symbolmonopol zu erwägen.

Die republikanische Presse legte nahe, daß die Dritte Republik die Monumentalisierung de la Barres mit der Absicht laizistischer Bekräftigung in der Kapitale unterstützte ${ }^{112}$, die konservative und katholische Presse setzte sich über die Denkmaleinweihung mit ebenso knappen wie vernichtenden Kommentaren hinweg ${ }^{113}$. Mit einer weiteren Denkmalerrichtung für de la Barre am

${ }^{106} \mathrm{Vgl}$. [An.,] Lettres de mon curé, S. 17f.

${ }^{107}$ Vgl. BARTHÉLÉMY, Erreurs, Bd. 14, S. 165-195, hier S. 175 sowie Bulletin du Congrès de Paris. Fédération Internationale de la Libre Pensée - Séction Française, S. 3, AN F ${ }^{\text {la }}$ I 170 Dossier: mai 1904-21 juillet 1905 Érection d'un monument au chevalier de la Barre, séance du 21 novembre 1904, in: CMPV, Année 1904, $2^{\mathrm{C}}$ sem., S. 678-80; Observations sur le Procès-verbal, séance du 25 novembre 1904, in: CMPV, Année 1904, $2^{e}$ sem., S. $713-$ 716, hier S. 713f.

${ }^{108}$ Vgl. Le Temps, 5. November 1906, S. 3; ibid. 6. November 1906, S. 3; Le Siècle, 5. November 1906, S. 2; REBÉRIOUX, La République radicale, S. 44-46.

${ }^{109}$ Vgl. Le Temps, 5. November 1906, S. 3.

${ }^{110} \mathrm{Vgl}$. ibid. 6. November 1906, S. 3.

${ }^{111}$ Vgl. ibid

112 Vgl. Le Temps, 5. November 1906, S. 3; Le Siècle, 5. November 1906, S. 2.

${ }^{113}$ Vgl. La Croix, 6. November 1906, S. 2; Le Gaulois, 5. November 1906, S. 2, 3; [An.,] Le Chevalier de la Barre. Son procès, ses bourreaux, o. O. 1905, S. 3f., 7; Goerges MONTORGUEIl, La vérité sur le Chevalier de la Barre. Extrait du Journal Eclair, Abbeville o. J. [1906], S. 7-11; Maurice D'AVRAY, Le procès du chevalier de la Barre: un crime judiciaire et une erreur d'opinion d'après les documents authentiques, préface de Henry DE GoUdOUR VILLE, Paris 1908, S. 5-14. 
historischen Ort des Geschehens in Abbeville im Sommer 1907 perpetuierten sich schließlich die in Paris eingeschliffenen Deutungen ${ }^{114}$.

Der solchermaßen angefeindete Katholizismus blieb eine monumentale Replik nicht schuldig: Bereits am 5. Juli 1908 wurde auf der Place de Montrouge im 14. Arrondissement auf Betreiben einer konservativen Fraktion im Conseil Municipal ein Denkmal für Michel Servet enthüllt, der, Arzt, katholischer Theologe und kritischer Humanist im Spanien des 16. Jahrhundert, von Calvin der Trinitätsleugnung bezichtigt, in Genf öffentlich verbrannt worden war ${ }^{115}$. Die Reden unternahmen gar nicht erst den Versuch einer nationsweit konsensualen Deutung, sondern zielten auf eine provokante Rückgabe des Intransigenz-Vorwurfs an die Antiklerikalen ${ }^{116}$. Die Replik entbehrte zeremoniellen und programmatischen Aufwands, stellte sich aber als durchaus selbstbewußte Verteidigung gegen die diffamierende Ausgrenzung des Katholizimus aus der Nation dar, den die Monumente für die laizistischen Märtyrer je neu betrieben hatten.

\section{Berlin: Konturen des Nationalprotestantismus}

Das Amalgam von nationaler und religiöser Loyalität wurde in der Berliner Denkmallandschaft in ungleich weniger konfliktträchtiger Form zum Thema und betraf fast ausschließlich den auf die Person Martin Luthers fixierten Nationalprotestantismus.

Weniger beachtet blieb demgegenüber zunächst das Ende Oktober 1885 eingeweihte Denkmal für den Schweizer Reformator Johannes Calvin auf dem Vorplatz des Hospizes der calvinistischen »Colonie« an der Großen Friedrichstraße. Schon im Festtermin kündigte sich eine staatszentrierte Deutung hugenottischer als Teil preußischer Geschichte an, denn als Jubiläumsdatum wurde nicht der Zeitpunkt der Niederlassung erster Exilfranzosen in Berlin 1672, sondern das kurfürstliche Edikt von Potsdam vom 29. Oktober 1685 veranschlagt, das Teilen der calvinistischen Minderheit in Frankreich Niederlassungsrechte in Brandenburg eingeräumt hatte, nachdem die Widerrufung des

${ }^{114}$ Vgl. WALTER, L'affaire La Barre, S. 367.

${ }^{115}$ Vgl. Le Petit Journal, 6. Juli 1908, S. 3; La Croix, 7. Juli 1908, S. 2.

${ }^{116}$ Vgl. Renvoi (...), séance du 7 décembre 1900, in: CMPV, Année 1900, $2^{\circ}$ sem., S. 1076; Questions, adoption des propositions, séance du 21 novembre 1904, in: CMPV, Année 1904, $2^{e}$ sem., S. 685-691; Observations sur le Procès-Verbal, séance du 25 novembre 1904, in: CMPV, Année 1904, $2^{\text {e }}$ sem., S. 713-716. 
Toleranzedikts von Nantes 1685 durch Ludwig XIV. sie in zeitgenössisch drastischem Ausmaß zur Massenabwanderung gezwungen hatte ${ }^{117}$.

Am bescheidenen Fest nahm neben mehreren Predigern der französischen Gemeinde unter anderem auch der deutsche Generalkonsul in London teil ${ }^{118}$. Für die demonstrative Einbettung der Feierlichkeiten in die preußischmonarchische Tradition sollte am folgenden Morgen eine feierliche Kranzniederlegung vor dem Denkmal Friedrichs des Großen Unter den Linden sorgen, vor dem Vertreter der französischen Kolonie einen mit schwarz-weiß-roten Atlasschleifen geschmückten Kranz postierten. Den ebenso religiösen wie herrschaftlichen Konnex zur Calvin-Figur stellte schließlich ein am Mittag zelebrierter großer Festgottesdienst in der Friedrichsstädtischen Kirche her, an dem neben Deputationen der Stadt auch der Kronprinz teilnahm ${ }^{119}$. Ein abendliches $\gg$ Familienfest« eröffnete darüber hinaus einen dezidiert bürgerlichen und dabei halb-offiziösen Festrahmen, indem sich hier noch einmal städtische Vertreter einschließlich des Oberbürgermeisters in den Räumlichkeiten der Philharmonie vor einem Tableau vivant mit einer überlebensgroßen Kolossalbüste des Großen Kurfürsten einfanden ${ }^{120}$.

Die Denkmalenthüllung selbst ging in der Fülle zeremonieller Einzelakte fast unter, die eher auf die historischen Hohenzollernherrscher und die regierende Dynastie ausgerichtet waren, bildete aber deren markanten Auftakt. Der Denkmalkomiteevorsitzende und Jurist d'Hargues skizzierte in seiner Festansprache die historische Leidensgeschichte der Hugenotten und feierte das Potsdamer Edikt, mit dem Friedrich Wilhelm von Brandenburg sein Land zu einem sicheren Fluchtpunkt für fast zwanzigtausend »Réfugiés» hatte werden lassen $^{121}$. Den Wechselfall von despotischer Vertreibung und gnädiger Aufnahme stilisierte d'Hargues zu einer Art Gründungs- und Integrationsmythos der französischen Gemeinde in Berlin, die in Preußen ihr "Vaterland « und einen Hort ihrer Kirche gefunden hatte ${ }^{122}$. Calvin illustrierte demzufolge die enge Symbiose von calvinistischem Credo und brandenburgisch-preußischem Staatsethos. Zugleich bestritt d'Hargues jegliche "Sonderinteressen« und

${ }^{117}$ Vgl. Frédéderic HARTWEg, Die Hugenotten in Berlin: Eine Geschichte, die vor 300 Jahren begann ..., in: DERS., Stefi JERSCH-WENZEL (Hg.), Die Hugenotten und das Refuge: Deutschland und Europa (Einzelveröffentlichungen der Historischen Kommission zu Berlin, 74), Berlin 1990, S. 1-56.

${ }^{118}$ Die Zeremonie eröffnete und schloß mit einem Choral und Hochrufen auf den Kaiser. Vgl. VZ, 29. Oktober 1885 (1. B.), S. 1; NZ, 28. Oktober 1885 (A.), S. 2. Im Anschluß wurden noch zwei Bronzereliefs am Koloniegebäude in der Klosterstraße enthüllt, die die Aufnahme der französischen Glaubensflüchtlinge durch den Großen Kurfürsten und die Einweihung der Berliner Kirche 1726 durch König Friedrich Wilhelm I. illustrierten; vgl. ibid.

119 Vgl. NAZ, 30. Oktober 1885 (M.), S. 2.

${ }^{120}$ Vgl. NZ, 29. Oktober 1885 (M., 1. Bbl.), S. 3.

121 Vgl. Eugène D'HARGUES, Rede zur Einweihung und Enthüllung des Calvin-Denkmals am 28. Oktober 1885 gehalten, Berlin o. J., S. 3-4.

${ }^{122} \mathrm{Vgl}$. ibid. S. 4. 
"formalistische Sonderheit ${ }^{123}$ der Calvinisten. Das defensive Votum spiegelte unfreiwillig Ressentiments gegen einen Sonderstatus ab, den man den Réfugiés und ihrer Kirche wiederholt unterstellt hatte, und den sie aufgrund der Beibehaltung ihrer französischen Nationalität, eigener Gerichtsbarkeit und der Pflege der französischen Sprachtradition in der Tat zunächst einnahmen, bevor die Stützpfeiler dieser Sonderexistenz während der napoleonischen Besetzung Preußens weggebrochen waren ${ }^{124}$. D'Hargues mühte sich demgegenüber um die Demonstration der Anknüpfungsfähigkeit der Calvin-Figur an den deutschen Protestantismus lutherischer Provenienz und zitierte zu diesem Zweck versöhnliche Voten Calvins über den deutschen Reformator ${ }^{125}$.

$\mathrm{DaB}$ die Integration der calvinistischen Hugenotten ins lutherische Preußen und Berlin wenige Jahrzehnte nach dem Ende des Dreißigjährigen Krieges und mitten im Konfessionellen Zeitalter durchaus auch Sprengstoff geboten hatte und die konfessionelle Koexistenz kein konfliktfreier Selbstläufer wurde, sollte so übergangen werden. Das loyale Bekenntnis zu »unserm Kaiser und (...) Vaterland ${ }^{126}$ sollte statt dessen dokumentieren, daß sich die Hugenotten mit dem Calvin-Denkmal ganz dem preußisch-monarchischen Nationsmythos zuordneten. Mythenkritischer Reflex auf die Inhomogenitäten der Hugenottenkolonie selbst und die Assimilationsschwierigkeiten während ihrer langen Geschichte bis 1885 oder auf die merkantilistischen Motive der preußischen Landesherren, die die Vertriebenen nicht nur aus Humanität, sondern auch auf dem Hintergrund eines handfesten ökonomischen Nutzenkalküls aufgenommen hatten ${ }^{127}$, war nicht zu hören und wurde auch von einer unemphatisch kommentierenden Presse nicht nachgeliefert ${ }^{128}$.

Die konfessionelle Verortung der Nation im Protestantismus wurde demgegenüber an zentraler Stelle über das Berliner Luther-Denkmal vorgenommen $^{129}$. Am 11. Juni 1895 wurde es nahe des Berliner Machtzentrums auf dem Neuen Markt vor der Marienkirche und nahe der Kaiser Wilhelmstraß $\mathrm{e}^{130}$, der "Künderin der neuen Reichshauptstadt an der Spree«, eingeweiht ${ }^{131}$. Als Eh-

${ }^{123} \mathrm{Ibid}$

${ }^{124}$ Vgl. HARTWEG, Die Hugenotten in Berlin, S. 10, 23, 31-48.

${ }^{125}$ Vgl. D'HARGUES, Rede, S. 10-13.

${ }^{126}$ Ibid. S. 14.

${ }^{127}$ Vgl. Stefi JERSCH-WENZEL, Toleranz und Ökonomie im 18. Jahrhundert, in: HARTWEG, DIES. (Hg.), Die Hugenotten und das Refuge, S. 147-157.

${ }^{128} \mathrm{Vgl}$. NZ, 28. Oktober 1885 (A.), S. 2.

${ }^{129}$ Vgl. Wolfgang STUMP, Lutherstandbilder als Nationaldenkmäler. Streiflichter zur Geschichte des Konfessionalismus in Deutschland im 19. Jahrhundert, in: Saeculum 34 (1983) S. 138-147; Wilhelm WEBER, Luther-Denkmäler - frühe Projekte und Verwirklichungen, in: MITTIG, PLAGEMANN (Hg.), Denkmäler im 19. Jahrhundert, S. 185-215.

${ }^{130}$ Vgl. DEMPS, Berlin - Wilhelmstraße, passim.

${ }^{131}$ Vgl. VZ, 11. Juni 1895 (M.), S. 4; ibid. 11. Juni 1895 (A., 1. B.), S. 1; NZ, 11. Juni 1895 (A.), S. 1-2; Freisinnige Zeitung, 12. Juni 1895 (Bbl.), LAB A Rep. 001-02 Nr. 267 [up]; 
rengäste fanden sich mehrere Minister, der Rektor der Universität und mehrere Theologieprofessoren, Vertreter der Kunstakademie und der Technischen Hochschule, der Stadtverordnetenversammlung und des Magistrats und mehrere Geistliche ein ${ }^{132}$. Obgleich das Komitee versucht hatte, den Kaiser selbst den Einweihungstermin festlegen zu lassen, um so seine legitimierende Teilnahme am Ritual zu gewährleisten ${ }^{133}$, erschien anstelle Wilhelms II. lediglich Prinz Friedrich Leopold. Choräle, Gebete und Glockengeläut prägten einen gottesdienstähnlichen Ritus.

Die Ansprache des Komiteevorsitzenden stellte den Initiativkontext der Denkmalstiftung her ${ }^{134}$ und verwies auf die 400-Jahrfeier des LutherGeburtstages $1883^{135}$, die als Ausdruck einer »starken christlichen Gefühlsbewegung« ausdrücklich religiös motiviert, zuleich aber politisiert wurde. Das reformatorische Ereignis erschien zwingend »auf deutscher Erde« anberaumt werden zu müssen, "wo der religiöse wie der politische Sinn des Volkes am häufigsten danach verlangt, (...) Kirche und Vaterland (...) umfassen zu dürfen ${ }^{136}$. Die deutsche Nation war demzufolge gleichermaßen zur Reformation dispositioniert wie in deren Verlauf ausgeprägt worden. Berlin wiederum bildete die Mitte dieser Nation, weil es als Zentrum der märkischen Reformation wie des neuen Deutschen Reichs fungierte. Die Doppelung von religiöser und politischer Relevanz betraf in der Rede vor allem die Luther-Figur selbst, die ebenso für "wahre Gottesfurcht" wie für "patriotische Hingabe an das Vaterland« stand und ein »Einheits《-Postulat für die »christliche« nicht anders als für die »nationale Gemeinschaft« verkörperte ${ }^{137}$.

Die Stilisierung Luthers zum Identitätsmittelpunkt eines unauflöslich amalgamierten Nationalprotestantismus wurde über die anachronistische Verzahnung von Reformation und Nationalstaatsgründung geleistet, allerdings so, daß der historisch-theologische Eigenwert des reformatorischen Prozesses weitgehend nivelliert und sein das Säkulare transzendierender Bedeutungshorizont

NPKZ, 11. Juni 1895 (A.), S. 1; und Programm für die Enthüllung des Luther-Denkmals auf dem Neuen Markt in Berlin, LAB A Rep. 001-02 Nr. 267 [up].

132 Anwesend waren u.a. der kaisernahe Vizepräsident des Staatsministeriums Heinrich von Boetticher, der Minister furr Handel und Gewerbe Hans Freiherr von Berlepsch, der liberale Finanzminister Johannes von Miquel, der ehemalige Innenminister Botho Graf zu Eulenburg, der Chef des Zivilkabinetts Hermann von Lucanus und der Oberpräsident von Brandenburg Heinrich von Achenbach.

${ }^{133} \mathrm{Vgl}$. Schreiben des Komitees an den Kaiser, 25. Mai 1895, GStA PK I. HA Rep. $89 \mathrm{Nr}$. 20887, Bl. 88.

${ }^{134} \mathrm{Vgl}$. Brief des Komitees an den König vom 7. November 1883, ibid. BI. 17; Aufruf für das auf dem Neuen Markt in Berlin zu errichtende Luther-Denkmal, Mai 1887, ibid. Bl. 42.

${ }^{135}$ Vgl. Johannes BURCKHARDT, Reformations- und Lutherfeiern. Die Verbürgerlichung der reformatorischen Jubiläumskultur, in: DÜDING u.a. (Hg.), Öffentliche Festkultur, S. 212236, hier S. 220, 225 und 228.

${ }^{136}$ VZ, 11. Juni 1895 (A., 1. B.), S. 1; NZ, 11. Juni 1895 (A.), S. 1-2, hier S. 1.

${ }^{137} \mathrm{Vgl}$. ibid. 
zugunsten der Reichseinigung verkürzt erschien. Oberbürgermeister Zelle schließlich, der das Denkmal im Namen der Stadt in Empfang nahm, ließ das religiös-konfessionelle Konnotationsfeld ganz aus und würdigte Luther als Schöpfer der "neudeutsche[n] Sprache, die alle verband und noch heute alle verbindet« und demnach als Initiator eines noch vor aller staatlichen Einheit homogenisierenden deutschen Kulturnationalismus.

Die liberale Presse übte sich weitgehend in der Reproduktion der entfalteten Deutungsmuster ${ }^{138}$, die sie gelegentlich mit kulturkämpferischem Duktus dramatisierte, indem sie sich noch einmal über den »finstere[n] Fanatismus« und die "Unduldsamkeit Roms" ereiferte, wovon sie Luther mit einer überschwänglichen Lichtmetaphorik als Symbol für den »Sieg des Lichts über die Finsternis, der Weisheit und Vernunft über Aberwitz und Verdummung« abhob $^{139}$. Als Quintessenz des reformatorischen Ereignisses erschien kein theologisches Argument, sondern das Bekenntnis zu rationalen Aufklärungswerten. Vor allem die National-Zeitung entwickelte noch einmal das preußischnationalprotestantische Dogma:

Sichtbare und unsichtbare (...) Mächte haben unsere Befreiung von dem napoleonischen Joche, die langsame politische Erziehung des deutschen Volkes und die endliche Errungenschaft unserer Einheit und Weltstellung herbeigefuihrt, aber unbestritten ist der entscheidende, den Ausschlag gebende, den Sieg gewinnende Antheil des Protestantismus, weil des preußischen Staates daran ${ }^{140}$.

Luther verbürgte mithin die enge, ebenso antirömische wie antinapoleonische Allianz von preußischem Nationalstaat und Protestantismus, und die Denkmalerrichtung bezeugte im zur konsensualen und ideal-inklusiven "Volksthat" stilisierten Stiftungsakt den konfessionellen Nationalkonsens. Neben die Idealisierung zum protestantischen Nationalhelden trat schließlich die komplette Verbürgerlichung der Figur, deren "Häuslichkeit« und "patriarchalische Würde« der National-Zeitung zufolge zugleich Lebenshaltungsmuster des traditionellen »deutsche[n] Pfarrhaus[es]« als einer der »segensreichesten Mächte in unserer nationalen Bildung« präfigurierten und die Nation ebenso als protestantische wie als bürgerliche Gemeinschaft identifizierten ${ }^{141}$.

Ganz im Sinne von Treitschkes gleichsam klassischer Luther-Deutung aus dem Jahr der großen Jubiläumsfeierlichkeiten 1883, die den Nationalisierungstrend der Luther-Feiern im 19. Jahrhundert wie im Brennglas eingefangen hatten ${ }^{142}$, begriff man den Reformator als »Führer der Nation« und »Volks-

${ }^{138}$ Vgl. VZ, 11. Juni 1895 (M.), S. 4.

${ }^{139}$ Vgl. ibid.

${ }^{140}$ NZ, 11. Juni 1895, S. 1; NZ, 31. Januar 1886, LAB A Rep. 001-02 Nr. 3274, BI. 34-36.

${ }^{141} \mathrm{Vgl}$. NZ, 11. Juni 1895 (M.), S. 1.

${ }^{142} \mathrm{Vgl.} \mathrm{Max} \mathrm{L.} \mathrm{BAEUMER,} \mathrm{Lutherfeiern} \mathrm{und} \mathrm{ihre} \mathrm{politische} \mathrm{Manipulation,} \mathrm{in:} \mathrm{GRIMM,}$ HERMAND (Hg.), Deutsche Feiern, S. 46-61, hier S. 51-57; Hartmut LeHMANN, Anmerkungen zur Entmythologisierung der Luthermythen 1883-1983, in: AKG 68 (1986) S. 457-477, hier S. 474-475. 
heilige[n]« und die Nation als dezidiert "protestantisches Volk ${ }^{143}$. Hatte Treitschke sich allerdings noch genötigt gesehen, sich gegen eine beliebige Politisierung der evangelischen Freiheitsidee im Sinne eines wwüthenden socialen Kampfe[s] « ${ }^{144} \mathrm{zu}$ verwahren, blieb 1895 jede $» F r e i h e i t s \ll-$ oder gar »Revolution[s] « ${ }^{145}$-Assoziation ausgeblendet. Waren schließlich die Luther-Feiern während des frühen 19. Jahrhunderts noch häufig auf der Basis einer integrativen Programmatik begangen worden und hatten in volksfestartigen Szenen bisweilen selbst Katholiken und Juden einbezogen ${ }^{146}$, blieben Prozedere und Sinnstiftungsradius in Berlin gegen Jahrhundertende enger. Der Transformation des religiösen Reformationsbekenntnisses zum säkularen Freiheitspostulat, die zur Emphase des Frühliberalismus gezählt hatte, war inzwischen die ebenso exklusive wie aggressiv antikatholische Verengung des Luther-Kults zum machtstaatskonformen nationalliberalen Votum gefolgt ${ }^{147}$.

Der Vorwärts zählte zu den wenigen Presseorganen, in denen entsprechende Verengungen wahrgenommen wurden. Zwar wartete er nicht mit programmatischen Verwerfungen auf, mokierte sich aber darüber, daß die Feier von der Militärmusik einer vom Tempelhofer Berg her vorbeiziehenden Truppenparade akustisch ausgerechnet zum Zeitpunkt der Enthüllung beeinträchtigt worden $\mathrm{sei}^{148}$. Das Prozedere ließ die Statue längst als "Lutherdenkmal im Militärstaat ${ }^{149}$ erscheinen, dem es aller emanzipatorisch-säkularen Rhetorik zum Trotz untergeordnet blieb.

${ }^{143} \mathrm{Vgl}$. Heinrich vON TREITSCHKE, Luther und die deutsche Nation. Vortrag, gehalten in Darmstadt am 7. November 1883, in: Preußische Jahrbücher 52 (1883), und wieder in: DERS., Historische und politische Aufsätze Bd. 4: Biographische und Historische Abhandlungen, Leipzig 1897, S. 377-396, hier S. 378.

144 Ibid. S. 379

${ }^{145}$ Ibid. S. 384.

${ }^{146}$ Vgl. BURCKHARDT, Reformations- und Lutherfeiern, S. 221-222.

${ }^{147}$ Weithin unbeachtet blieb das an der Südseite des Schlosses am Lustgarten Mitte Februar 1905 eingeweihte Denkmal für Coligny. Vgl. NAZ, 17. Februar 1905, S. 2. Die NZ, 16. Februar 1905, S. 3, begründete die Denkmalerrichtung mit Colignys weitläufiger Verwandtschaft mit dem Kaiser. Die Denkmalsetzung wurde so zum privaten Akt pietätvoller Ahnenwürdigung.

${ }^{148} \mathrm{Vgl}$. Vorwärts, 12. Juni 1895 (I. B.), S. 3.

${ }^{149}$ Ibid. 


\section{London: Zwischen konfessionellen Pluralismen und anglikanischem Deutungsprimat}

$\mathrm{Ab}$ den 1880 er Jahren entstanden in loser Folge bis zur Jahrhundertwende vor allem drei öffentliche Denkmäler, deren Stifter die jeweils repräsentierten Denominationen mit einer unterschiedlich aufwendigen Programmatik mit der Nation in Verbindung setzten. Zunächst erhielt Anfang Mai 1884 der Reformator des 16. Jahrhunderts William Tyndale eine Statue am Victoria Embankment ${ }^{150}$. Programmatisch hatte sich zum Denkmal bereits 1879 der zur etablierten »broad church« zählende Dean von Westminster, Stanley, im Rahmen einer ersten konstituierenden Sitzung des Denkmalkomitees in London geäußert: „On the Continent the Reformation was personified in different individuals; the English Reformation was, more properly speaking, the result of the national movement. (...) William Tyndale (...) represented the popular and lay feeling of the Reformation ${ }^{151}$. Stanley ging hier nicht bis zum Aufbegehren des englischen Monarchen Heinrich VIII. gegen den Papst Anfang des 16. Jahrhunderts als zunächst einmal dynastisch motiviertem Initialakt der englischen Reformation zurück. Statt dessen schrieb er der englischen Reformation einen von Beginn an volksnahen Charakter zu, den sie faktisch erst durch die vom König lancierte Involvierung des Parlaments angenommen hatte, weil nun Fragen kollidierender Jurisdiktion und exzessiv prunkhafter Selbstdarstellung der Kirche zum Politikum hatten geraten können ${ }^{152}$. Bedeutsamer als die These, daß die englische weniger als die kontinentale Reformation in ihrem weiteren Verlauf von Eliten vorangetrieben worden sei, blieb der Umstand, daß Stanley einen Sonderweg für England im Vergleich zum Kontinent reklamierte. Daß sich die Grundthese von der Kopplung nationaler und konfessioneller Loyalität im europäischen Vergleich, wenn auch unter je eigenen Vorzeichen, nicht wirklich spezifisch ausnahm, wurde nicht erkannt.

Die feierliche Enthüllung 1884 in Anwesenheit zahlreicher Subskribenten und Komiteemitglieder, darunter mindestens zehn Geistliche auch von außerhalb Londons, folgte einem gottesdienstähnlichen Ritus ${ }^{153}$. Nicht zuletzt der bescheidenen Inszenierung wegen fand die Denkmalenthüllung kaum Widerhall und selbst die Times, die die Genese der Statue immerhin noch phasen-

${ }^{150}$ Vgl. The Times, 26. Juni 1879, S. 7

${ }^{151}$ Ibid.

${ }^{152}$ Vgl. Heiner HAAN, Gottfried NIEDHART, Geschichte Englands vom 16. bis zum 18. Jahrhundert, München 1993, S. 121-136. Die Charakterisierung der Reformation als volksnah-unelitäre Bewegung rekurrierte womöglich auf die emanzipatorische Freigabe der Bibellektüre Ende der 1630er Jahre, die allerdings wenige Jahre nach dem Sturz Cromwells 1643 wieder rückgängig gemacht worden war, um den reformatorischen Diskurs eben doch auf die gesellschaftliche Elite zu beschränken; vgl. ibid. S. 127.

${ }^{153}$ Vgl. The Times, 8. Mai 1884, S. 4. 
weise verfolgt hatte, enthielt sich weiterer Kommentare. Für Obstruktionsvorwürfe gegen einen inquisitorischen Katholizismus, dem die öffentliche Verbrennung des Märtyrers Tyndale an vergleichbarer Stelle wohl in Paris zugeschrieben worden wäre, blieb angesichts einer derart wenig prononcierten Programmatik kein Raum.

Mit deutlicher Verzögerung folgte Anfang März 1891 eine Statue für den Methodistenprediger John Wesley vor der von ihm im April 1777 gegründeten Kirche in der City Road. Dazu versammelte sich eine stattliche Festgemeinde vor der City Road Chapel, die an diesem Tag auch den hundertjährigen Todestag Wesleys im Rahmen offizieller Feierlichkeiten der methodistischen Kirche beging. Anwesend waren neben dem Hauptzelebranten, dem Geistlichen und Präsidenten der Wesleyan Conference William Moulton, weiter als Vertreter der Church of England Erzdiakon Frederic W. Farrar und aus dem Parlament der methodistische Liberale Henry Fowler, mehrere Expräsidenten der methodistischen Konferenz, darunter auch aus Irland, und Repräsentanten pietistischer Untergliederungen, deren Präsenz zugleich die starke Binnendifferenzierung der Konfession dokumentierte ${ }^{154}$. Der Denkmalenthüllung mit Choral und Gebet folgte ein aufwendiger Festgottesdienst, in dessen liturgischen Rahmen sie damit vollends absorbiert schien ${ }^{155}$.

Unter den Festrednern machte bereits Moulton die Bedeutung des Denkmals weit über den Einzugsbereich des "Methodism« als der von Wesley begründeten Denomination hinaus für jeden »English citizen « geltend ${ }^{156}$. Erzdiakon Farrar bekundete im Namen der anglikanischen Staatskirche Dialogbereitschaft und religiöse Verbundenheit über alle konfessionellen Differenzen hinweg. Daß keine institutionelle Einbindung Wesleys und seiner Anhänger in die traditionelle Kirchenhierarchie dem Konfessionsschisma hatte vorbeugen können, wurde bedauert, zugleich aber als Defizit einer zu Wesleys Zeiten in der zweiten Hälfte des 18. Jahrhunderts »lazy and lukewarm « gewordenen Staatskirche eingestanden ${ }^{157}$. Als Wesleys Verdienst um die Nation verblieb die Hebung religiöser Moral der "great masses of the people«, die auch die "dispairing « und »outcasts« erreichte ${ }^{158}$. Daß Wesley die religiöse Integration gerade der sozial und politisch marginalisierten Unterschicht in der vorindustriellen Gesellschaft der Nation eröffnete, qualifizierte ihn in den Augen Farrars mehr als nationale Kultfigur denn jeden »soldier and sailor.« Implizit verwies Farrar damit zugleich auf die »poor « und »humble« als die noch bis ins 19. Jahrhundert hinein ausgegrenzten Verlierer des ökonomischen Fort-

\footnotetext{
${ }^{154}$ Vgl. The Times, 3. März 1891, S. 10; The Standard, 3. März 1891, S. 3; The Guardian, 4. März 1891, S. 5 und 8.

155 Vgl. ibid.

156 Vgl. ibid.

${ }^{157} \mathrm{Vgl}$. ibid. 16 Jahre zuvor erhielt Wesley allerdings in Westminster Abbey eine Gedenktafel.

158 Vgl. ibid.
} 
schritts und meldete stellvertretend für sie Inklusionsbedarf an, den Wesley durch seine Erweckungsbewegung auf spiritueller Ebene zu decken verstanden hatte.

Der Abgeordnete und bekennende Methodist Fowler politisierte anschlieBend sein Argument stärker und interpretierte Wesleys Maxime "what is morally wrong can never be politically right ${ }^{159}$ als indirekte, aber zeitlose Anklage gegen eine nationale Ordnung, deren ökonomische und politische Effizienz mit drastisch hohen sozialen Kosten verbunden war: "The noblest result of the religious revival was the steady attempt, which has never ceased from that day to this, to remedy the guilts, the ignorance, the physical suffering, and the social degradations of the profligate and the poor ${ }^{160}$. Daß die Inklusionsleistung der religiösen Bewegung, die bereits im vorausgehenden Jahrhundert politisch zu verantwortende soziale Ungleichheit kompensieren mußte, einem religiös-moralisch inspirierten Nationskonzept des ausgehenden 19. Jahrhunderts als Vorlage dienen sollte, blieb das angedeutete Postulat, um das Fowlers Rede kreiste. Die Wesley-Figur diente mithin den Denkmalinitiatoren und Rednern dazu, nicht nur den puritanischen Dissent als weithin gleichberechtigte Denomination neben die anglikanische Staatskirche zu stellen, sondern auch dessen eigenen, konstitutiven und weiterhin exemplarischen Beitrag zur religiösen Kultur der Nation zu würdigen. Die Erinnerung an die spirituelle Sorge um und für die sozial, politisch und ökonomisch Benachteiligten blieb als subtil-unbequeme Anfrage an die aktuelle soziale Binnenstruktur der nationalen Gesellschaft angedeutet.

Während die Times und der Standard ebenso ausführlich wie neutral berichteten $^{161}$, zog der dem Dissent zugehörige Nonconformist and Independent eher theologische Konsequenzen aus der Feier der Wesley-Figur, indem er nach erneuter Annäherung zwischen dem alten puritanischen Dissent und dem evangelikalen Methodismus verlangte ${ }^{162}$. Insgesamt blieb zumindest das politische Echo auf die Denkmalenthüllung verhalten. Verständlich nahm sich vor diesem Hintergrund der im Standard veröffentlichte Leserbrief aus, in dem ein James W. Mayer auf die Abwesenheit offizieller Regierungsvertreter oder Gesandter der Krone verwies und die Königin provokant aufforderte, den Feierlichkeiten Aufmerksamkeit zu zollen und damit zur Kenntnis zu nehmen, daß auch »some two millions of Her Majesty's subjects in the British Isles« zu-

${ }^{159}$ Ibid.

${ }^{160}$ Ibid.

${ }^{161}$ Vgl. The Times, 3. März 1891, S. 10; The Standard, 3. März 1891, S. 3; Lloyd’s Weekly Newspaper, 8. März 1891, S. 6.

${ }^{162}$ Vgl. The Nonconformist and Independent, 6. März 1891, S. 150. Den Vorwurf gegen Wesley, mit dem papistischen Arminianismus im Bund zu stehen, der im Vorfeld der Englischen Revolutionen massiven puritanischen Widerstand provoziert hatte, wollte der Independent entkräften. Wesleys Abgrenzung von der puritanisch-calvinistischen Prädestinationslehre sah er nicht als arminianistische Anwandlung, sondern als dogmatische Synthese. 
gleich Nonkonformisten und loyale Anhänger der Krone waren ${ }^{163}$. Angesichts des Wesley-Denkmals forderte Mayer damit nichts Geringeres als eine eigens vom Oberhaupt der etablierten anglikanischen Staatskirche ausgehende Geste, die die Kompatibilität von monarchisch-nationaler Gesinnung und Dissent offiziell anerkannte.

Einen dritten konfessionellen Akzent setzte schließlich Mitte Juli 1896 das Denkmal für Kardinal John Henry Newman, den vehementen Reformgegner und Exponenten des bereits seit den 1830er Jahren seitens der anglikanischen Kirche unter Papismusverdacht gestellten Oxford Movement, der im Oktober 1845 zum Katholizismus konvertiert war und schließlich 1879 die Kardinalswürde erlangt hatte. Seine Marmorstatue wurde vor dem Brompton Oratory direkt an der östlichen Seite des Museumskomplexes von South Kensington eingeweiht ${ }^{164}$. Bereits der Umstand, daß nicht nur Vertreter der katholischen Kirche, sondern auch ein anglikanischer Geistlicher dabei das Wort ergriffen, signalisierte ähnlich wie anläßlich bei der Wesley-Feier, daß eine konsensuale Zeichensetzung beabsichtigt und zumindest der rituellen Praxis nach zunächst auch gelungen war.

Die meisten Redner hielten sich mit Ausführungen zu Newmans Theologie zurück, um Rücksicht auf die Religiosität andersgläubiger Teilnehmer der Versammlung zu nehmen. Die Stilisierung Newmans zur Kultfigur fand insofern nach Maßgabe klarer offizieller Sprachregelungen statt. Sie erwies sich nur dadurch als möglich, daß seine katholischen oder mit dem Katholizismus sympathisierenden Anhänger auf explizite konfessionelle Bekenntnisse verzichteten, mithin eine Art anglikanisches Deutungsprimat respektierten, ohne zugleich ein Sinnstiftungsmonopol der Church of England anzuerkennen. Zu dieser Strategie gehörte auch der Versuch, sich auf kompromißfähiges Deutungsterrain zu begeben, indem die Denkmalstifter Newman einer affektbetonten Anerkennung durch das Publikum empfahlen ${ }^{165}$. Auch der anglikanische Dean of Durham, Lake, rekurrierte auf Newman nicht als Exponent des Oxford Movement, sondern als theologisch gewissenhaften Akademiker. Der interkonfessionelle Antagonismus wurde zugleich mit einem mahnenden Verweis auf die ungleich tieferreichende Fundamentaldifferenz zwischen religiöser und säkularer Werthaltung beschwichtigt. Demgegenüber beschwor Lake nun die Verwurzelung der englischen Nation weniger konkret im Anglikanis-

${ }^{163}$ Vgl. The Standard, 4. März 1891, S. 3.

${ }^{164}$ Vgl. zum Folgenden The Times, 16. Juli 1896, S. 12; The Standard, 16. Juli 1896, S. 4; extrem knapp The Guardian, 16. Juli 1896, S. 5. Anwesend waren der anglikanische Dean von Durham, William Lake und der katholische Herausgeber der Dublin Review und Newman-Biograph Wilfrid Ward.

${ }^{165}$ Vgl. The Daily Telegraph, 16. Juli 1896, S. 7; The Times, 16. Juli 1896, S. 12. 
mus als in einem $»$ definite Christian belief ${ }^{166}$. Damit blieben religiöse und nationale Loyalität eng verbunden, während jede Spielart areligiöser Weltsicht als mit der englischen Nation inkompatibel galt, so daß sich gleichsam die Feindbildkonstellation von der konfessionellen Konfliktlinie wegverschob. Andere Laudatoren umgingen prekäre Einordnungen, indem sie sich ausschließlich auf Newmans akademisches Wirken und seine theologischen und historiographischen Schriften kaprizierten.

Ein in fast allen Redebeiträgen auftauchender Hinweis machte am Ende das Kultarrangement durchsichtig, das die Monumentalisierung eines Katholiken ohne unmittelbare argumentative Gegenwehr seitens des etablierten Anglikanismus ermöglichte: Just am gleichen Tag nämlich inszenierte die Church of England einen konkurrierenden Symbolakt, indem sie in Westminster Abbey eine Büste für den bereits 1842 verstorbenen Historiker und Theologen Thomas Arnold enthüllen ließ, dessen Engagement für einen landesweit verwurzelten Broad Church Anglicanism ihn als Bürgen jenes Werteamalgams aus anglikanischer Staatskonfession und nationaler Gesinnung erscheinen ließ, die der Newman-Figur kontrapunktisch und am prominenten Kultort entgegengesetzt werden konnte ${ }^{167}$. Nicht nur, daß die Symbolkonkurrenz gezielt inszeniert, sondern daß sie den nicht-katholischen Rednern anläßlich der Enthüllung des Newman-Denkmals auch längst schon zur Vergewisserung dieses traditionalen Werteamalgams dienen konnte, zeugte vom Erfolg der Strategie, die katholische Kultfigur auf dem Hintergrund dieser Symbolkonkurrenz zuzulassen. $\mathrm{DaB}$ schließlich die Errichtung der Newman-Statue in London sich letztlich einer mißglückten Monumentalisierung in Oxford verdankte, die dort am vehementen Widerspruch von Universität und Öffentlichkeit und nicht zuletzt weiter Teile der Presse gescheitert war, die das antikatholische Votum zum Schulterschluß zwischen anglikanischer Staatskirche und Dissent nutzte ${ }^{168}$, signalisierte endgültig den äußerst prekären und keineswegs konsensualen Diskurs um die Newman-Figur.

Der Standard indessen beschloß, die Doppelung der Denkmaleinweihungen nicht als Akt der Konkurrenz, sondern als Symbolbalance zu werten und hob ganz im Sinne der Reden hervor, daß Newman und Arnold jenseits aller Differenzen für eine konfessionsunabhängige moralische und intellektuelle Selbst-

${ }^{166} \mathrm{Vgl}$. ibid.: $)$ It was to him [i.e. Newman, H.R.] more than to anyone else in an age of great doubt, that we owed the continuance (...) of definite Christian belief. (...) all sincere and deep-minded Christians, to whatever body they belonged, must acknowledge Newman as a warm upholder of the faith.«

${ }^{167}$ Vgl. The Standard, 16. Juli 1896, S. 5. Bei der Enthüllung der Amold-Büste in Westminster Abbey in Anwesenheit des Erzbischofs von Canterbury fehlte jeder Rekurs auf die am gleichen Tag aufgestellte Newman-Statue.

168 Vgl. The Times, 25. Januar 1892, S. 4; ibid. 27. Januar 1892, S. 7; ibid. 2. Februar 1892, S. 9,10 ; ibid. 4. Februar 1892, S. 9. 
verpflichtung der nationalen Gesellschaft standen ${ }^{169}$. Am Ende hielt der Standard an der Diskreditierung der katholischen Kirche bei gleichzeitiger Würdigung Newmans fest, indem er argumentierte, daß die »Roman Church « ohnedies Newman nie ganz zu absorbieren vermochte, weil seine anglikanische Glaubensherkunft ihn zeitlebens zur distinkten Erscheinung und unter anderem zum vehementen Gegner des päpstlichen Unfehlbarkeitsdogmas machte ${ }^{170}$. Deutliche Abstufungen waren gleichwohl auch in der versöhnlichen Deutung des Standard erkennbar, indem er Arnold ungleich emphatischer würdigte. Nur ihm wurden Verdienste um das anglikanisch ausgerichtete Bildungssystem zum einen und um das "British Empire « und den intellektuellen und moralischen Status seiner Eliten zum anderen bescheinigt ${ }^{171}$. Daß die brilliantere nationale Kultfigur derjenige der Geehrten abgab, der das nationale mit dem anglikanischen Credo kombinierte, wurde ebenso deutlich wie unpolemisch nahegelegt.

\section{Vergleich}

Die thematische Zuordnung von religiöser Loyalität und Nation erwies sich für alle drei Symbollandschaften als grundlegendes Bedürfnis zeitgenössischer Diskutanten. Im Falle der Jeanne d'Arc-Denkmäler stand deren in der Regel unspektakuläre und flüchtig-inoffiziöse Plazierung im Widerspruch zur Zentralität, die die Figur im nationalen Diskurs Frankreichs einnahm.

Wichtiger als die Einweihungsfeierlichkeiten ist für alle Jeanne-Statuen, besonders aber für die erste von $\mathbf{1 8 7 4}$ auf der Place des Pyramides, deren rezeptive Nachwirkung in Gestalt der je neuen Demonstrationen vor dem Denkmal geworden. Weil der Versuch einer definitiven republikanischen Vereinnahmung in Gestalt einer unmißverständlichen Inschrift fehlschlug, behielt das Denkmal eine Ambivalenz, die je neu wieder vereindeutigt werden konnte. Zum Modus des Symbolkonflikts am Denkmal avancierte unter diesen Umständen die Niederlegung von Kränzen mit Widmungsschleifen, die den Kampf um Deutungshoheiten drastisch dynamisierten, wie das andauernde Plazieren oder Entfernen von temporären Inschriften über die öffentliche Konnotierung des Denkmals entschied. Eine vergleichbare Form ephemerer Sinnzuschreibungskonkurrenzen auf ein und dieselbe Figur hat es weder in Berlin noch in London in dieser Form gegeben. Auch dort war der Modus der Kranz-

\footnotetext{
${ }^{169} \mathrm{Vgl}$. The Standard, 16. Juli 1896, S. 7.

${ }^{170}$ Vgl. ibid.

171 Vgl. ibid.
} 
niederlegung zum Zweck öffentlicher Loyalitätsbekundung üblich, changierte aber nicht zwischen oppositionellen Fraktionen, sondern zwischen Deutungsmonopolisten und ihren Gegnern.

In zeremonieller Hinsicht weitgehend konfliktfrei gingen unterdessen die übrigen Errichtungen zahlreicher laizistisch intendierter Denkmäler in Paris vonstatten. Der Kultus blieb vor allem anläßlich der ersten Denkmalerrichtung für Voltaire Mitte der 1880er Jahre, die unter Beteiligung hochrangigen Personals vonstatten gehen konnte, unbeschadet und wurde auch im Rahmen des ohnedies unscheinbareren zweiten Denkmalfestes nur peripher beeinträchtigt. Gleiches galt für die Einweihung der Dolet-Statue Ende der 1880er Jahre, die im Jahr der Centenaire-Feierlichkeiten der Revolution von 1789 demonstrativ einem republikanischen Inszenierungsmodus einschließlich der Marseillaise und einem Festzug folgte. Eine besonders enge politische Adaption an die republikanische Nation unternahmen in ostentativer Nähe zum Nationalfeiertag auch die protestantischen Stifter der Coligny-Figur, erhielten hier allerdings ebensowenig wie die Dolet-Zelebranten Unterstützung durch offizielles Regierungspersonal und zogen sich ohnedies für den überwiegenden Teil der Feier in den kirchlichen Innenraum zurück.

Ungleich unspektakulärer verliefen demgegenüber die Berliner Denkmalsetzungen gleicher thematischer Zielrichtung, bei denen es weder zu einem besonders hohen zeremoniellen Aufgebot noch zu öffentlichen Deutungskonflikten kam. Im auffälligen Gegensatz zu den Pariser standen aber vor allem die Londoner Denkmalsetzungen, die, obschon sie Repräsentanten unterschiedlicher konfessioneller Provenienz galten, formell konsensual und nicht im Sinne des monumentalen Schlagabtauschs zustande kamen. Das Konsensmoment der Londoner Initiativen kam auf ritueller Ebene im Falle des methodistischen Wesley- wie des katholischen Newman-Denkmals durch die unmittelbare und aktive Einbeziehung anderskonfessioneller Vertreter zustande, die nicht nur als Teilnehmer, sondern auch als Redner im Programm berücksichtigt wurden. Eine derart weitgehende zeremonielle Inklusion ist im Vergleich zu Paris oder Berlin ohne Pendant geblieben. Allerdings war die konsensuale Feier des Londoner Denkmals für den Repräsentanten des Katholizismus wenig anders als in Paris nur vor dem Hintergrund einer monumentalen Replik möglich, die mit dem Arnold-Denkmal zeitgleich in Westminster gegeben wurde; die rituelle Kollision konnte hier also durch einen direkt konkurrierenden Symbolakt aufgefangen werden.

In programmatischer Hinsicht bildete in Paris die Verortung der Nation in säkularen oder religiösen Sinnkontexten einen der zentralen Themenschwerpunkte nationalen Diskurses spätestens seit Gründung der Dritten Republik. Die spezifische Brisanz religiöser Konnotationen bestand dabei in ihrer unmittelbaren Verquickung mit system- und bisweilen sozialpolitischen Optionen, indem die Laizismus/Katholizismus- oder Antiklerikalismus/Klerikalis- 
mus-Konstellation dem unversöhnlichen Gegensatz zwischen republikanischen und konservativ-monarchistischen Zielutopien entsprach.

Das Jeanne-Denkmal auf der Place des Pyramides von 1874 wurde von Beginn an zum Gegenstand konkurrierender Sinnzuschreibungen, die in beiden Fällen auf eine reiche historiographische Tradition zurückgreifen konnten. Die Jeanne-Legende bezog sich in der republikanischen Version auf die "fille du peuple« als Repräsentantin der säkularen, antimonarchischen Nation, während sie nach katholisch-konservativer Lesart den Autoritäten Kirche und Monarchie zugeordnet war und in ihrer reaktionären Variante sogar die monarchische Überwindung der Republik als Teil einer provokanten politischen HeilsverheiBung virulent erscheinen lassen konnte. Im polemischen Schlagabtausch spielte die denkmaltopographische Verortung der Statue im Pariser Symbolterrain eine denkbar wichtige Rolle. Konservative nicht anders als republikanische Deuter korrelierten die Jeanne-Statue gleichermaßen symbolisch mit der Vendômesäule, um im einen Falle in beiden Monumenten Reminiszenzen an die historische Unterlegenheit, aber gleichzeitig neue Präsenz der monarchischen Nation, im anderen eine symbolische Vorwegnahme der glorreichen republikanischen Zukunft Frankreichs zu erkennen. Damit spiegelte die Rezeption des Jeanne-Denkmals auch noch einmal eindringlich die äußerst ambivalente Sicht auf den Symboleffekt wider, den die Wiedererrichtung der Vendômesäule anders als von der Thiers-Regierung der frühen Republik beabsichtigt faktisch ermöglichte.

Die ungebrochene doppelte Okkupation beider Monumente im Zentrum der Kapitale blieb sowohl innerhalb von Paris als auch im Vergleich singulär und erwies sich als genuiner Effekt einer von zahlreichen Kontinuitätsbrüchen gekennzeichneten Geschichte Frankreichs. In deren Folge erschien der Prozeß von Etablierung und Verlust von Deutungshoheiten, von Mythos und Antimythos sprunghaft beschleunigt, während mit der Häufigkeit der Zusammenbrüche nicht einfach nur Wechsel der Deutungsmonopole stattfanden, sondern eine Art subkutane Deutungsebene entstand, auf der die historisch unterlegenen Nationsbilder weiter virulent waren. Hier blieben sie entweder latent, wenn die herrschenden Mythenbildner sie unterbanden, oder brachen als konkurrierende Legende hervor, wenn dies irgend statthaft war. Der französische Jeanne-Diskurs trug dabei immer beide Züge - die relativer Inklusion, indem monarchische Gegner des republikanischen Kults sich überhaupt öffentlich artikulieren konnten, und Züge der Exklusion, indem beide Lesarten den Status der Orthodoxie beanspruchten und somit die republikanischen Jeanne-Apologeten im Disput sowohl dem Katholizismus als auch der monarchischen Reaktion die Kompatibilitåt mit der Nation grundsätzlich absprachen.

Eine vergleichbare sinnhafte Doppelbelegung eines Denkmals nicht mit einer Legende und ihrer die jeweilige Figur verfemenden Antilegende, sondern mit zwei konkurrierenden positiven Mythen, hat es so weder in Berlin noch in 
London gegeben. In Großbritannien standen im Disput um die Cromwell-Figur nur Denkmalbefürworter und -gegner gegeneinander, während die Sinnzuweisungen für das einmal errichtete Denkmal zu einschlägig waren, um für Zweitmythen zu taugen. In Berlin hat demgegenüber die Rigidität, mit der unerwünschte Nationsdeutungen abgedrängt wurden, und wohl auch der mangelnde Elan, mit dem beispielsweise ein liberaler Antimythos konsequent auch auf die Monarchendenkmäler hätte projiziert werden können, entsprechende Kollisionen bereits im Vorfeld unterbunden.

$\mathrm{Zu}$ Kultverboten ist es zwar gerade im Zusammenhang mit den Querelen um die Gedenktage für Jeanne und Voltaire auch in Frankreich gekommen, der royalistische Jeanne-Kult konnte aber auf diesem Wege nicht einfach verdrängt werden. Dabei ist die Parallelität der nationalen Jeanne-Mythen im Umfeld der Denkmäler auch deshalb erhalten geblieben, weil Jeanne als Hoffnungsträgerin für die 1871 gedemütigte Nation immer konsensfähig blieb. Ungeachtet konkreter Konnotierungen eröffnete sich vom Niederlagentopos her ein Erwartungs- und Verheißungshorizont für die rekonvaleszente und revanchebefugte Nation, die den Kultstatus der Figur unhintergehbar erscheinen ließ. Es lag in der Logik dieses freilich vagen Konsensvorrats, daß nach der Jahrhundertwende auch der extrem rechte Ligennationalismus Anläufe unternahm, sich ihrer zu bemächtigen. Das Kalkül, mit dem die Patriotenliga sich den Katholiken andiente, um die Republik symbolisch auszumanövrieren, zielte auf die Teilhabe am Kult um eine späte Lichtgestalt der Revanche.

Voltaire war anders als die Jeanne- und ähnlich wie die meisten übrigen französischen und europäischen Kultfiguren Gegenstand oppositioneller Konnotationen und kam überhaupt nur für eine der opponierenden Deutergruppen als Kultfigur infrage. Bereits in der liberalen Endphase des Zweiten Empire erschien Voltaire als Hoffnungsträger für die Verfechter der republikanischlaizistischen Nation und als Inbegriff eines antinapoleonischen und autoritätskritischen Antitraditionalismus; Symbolmacht war für diese Deutung aber noch nicht zu gewinnen. Institutionell gesichert dominierte demgegenüber ein katholisch infiltrierter Nationalismus, der die Voltaire-Apologien nicht nur unterdrückte, weil der säkulare Sinnhorizont mißfiel, in den Voltaire die Nation rückte, sondern auch, weil er um die hochpolitische Funktion und Sprengkraft des Antiklerikalismus wußte, der Republikaner und Radikale zur gemeinsamen Frontbildung gegen das Empire ermutigte.

Nach der Gründung der Dritten Republik trat im republikanischen VoltaireKult das Argument der Emanzipation von der autoritären Monarchie hinter dem der laizistischen Traditionsstiftung zurück. Entsprechend firmierte Voltaire verstärkt als geistiger Vorreiter der Revolution. Das an ihn angelehnte Nationsbild zielte auf die legitimatorische Berufung auf die Freiheitstraditionen von 1789. Kontinuitätskonstrukte und teleologische Denkfiguren, wie sie vor allem im Zusammenhang mit den Berliner Monarchendenkmälern aufgetaucht 
waren, erwiesen sich hier wie schon im Blick auf anderes Personal erneut auch im republikanischen Frankreich als allgegenwärtige Legitimationslogik.

$\mathrm{Da}$ B die Monumentalisierung Voltaires als Inbegriff eines säkularen Nationsbildners in der Frühphase der Dritten Republik zunächst mißlang, war einer vorübergehenden Beschwichtigungspolitik des opportunistisch-gemäßigten, liberalen Republikanismus geschuldet, der die Exklusionsrhetorik zunächst auf Kosten der Katholiken mied. Im gleichen Maße, in dem der Antiklerikalismus unter den Bedingungen massiven innenpolitischen Wandels zum ideologischen Verbindungsstück zwischen moderatem Republikanismus und radikaler Linker avancierte und der Konservativismus im Anschluß an seine fehlgeschlagenen Attacken gegen die Republik an Schwungkraft einbüßte, erhielt der Voltairianismus allerdings Auftrieb und ermöglichte dann doch noch die Denkmalsetzung.

In den Tiraden der katholischen Presse spiegelte sich demgegenüber die Taktik wider, den Kult des Säkularen als metaphysische Bankrotterklärung der republikanischen Nation zu werten. Die kurzfristige Verquickung des Aufklärungsphilosophen mit der munizipalen Autonomiedebatte des 19. Jahrhunderts anläßlich der zweiten Denkmalsetzung 1887 zeugte vom bisweilen manipulativ-elastischen Charakter der Sinnprojektionen, mit denen nicht nur dezidiert nationale Belange vermittelt werden sollten.

Zum ausgehenden Jahrhundert hin verschärfte sich im Umfeld Pariser Denkmalinitiativen in einem in London wie Berlin ungekannten Ausmaß nicht nur der polemische Ton gegenseitiger Attacken, sondern zusehends auch das Tempo, mit dem die Denkmalsetzungspraxis sich hier regelrecht zum monumentalen Schlagabtausch auswuchs. In der Feier des Dolet-Denkmals 1889 setzte sich vor dem Hintergrund einer noch von den Attacken des Boulangismus genesenden republikanischen Kultur zunächst noch das antiklerikale Votum der Republikaner fort, gleichsam als Maßnahme der politischen Selbstversicherung und in der Tradition der Grundsatzentscheidungen über die weitgehende Trennung von Kirche und Staat, die die Opportunisten in den 1880er Jahren getroffen hatten.

Mit gesteigert aggressiven Tönen meldeten sich als Apologeten der antiklerikalen Nation nach der Jahrhundertwende vor allem die Stifter des de la Barre-Monuments zurück. Die Exklusionsformel gegen den Katholizismus hatte inzwischen nachgerade dogmatische Züge angenommen, und so bildete die Denkmalprogrammatik hier nur jenen verbal militanten, tendenziell hysterischen Antiklerikalismus ab, den ein inzwischen an die Macht gekommener Linksradikalismus und Sozialismus zur ehernen Konsensformel auserkoren hatte, um über vielfache Friktionen hinweg die Machtallianz zusammenzuhalten. Das vehemente Exklusionspathos gegenüber dem Katholizismus war insofern eher einer linken Mobilisierungs- und Solidarisierungstaktik als einer permanenten Emphase über der Idee der laizistischen Nation geschuldet. 
Dennoch gelang dem Katholizismus in den Jahren nach der erneuten antiklerikalen Aufwallung, als durchaus wieder nach einem modus vivendi mit dem Katholizismus gesucht wurde, die Aufstellung des Servet-Denkmals, mit dem sich der Katholizismus auch in nationaler Absicht wieder zu Wort meldete. Der monumentale und programmatische Diskurs hat sich in Paris jedenfalls an dieser Stelle ähnlich wie im Blick auf die Jeanne-Gestalt im europäischen Vergleich weitgehend verselbständigt. Einer dezidiert laizistischen Nation ist weder in London noch in Berlin mit öffentlichen Denkmälern gehuldigt worden, ebenso wie ein auch nur annähernd vergleichbarer, nicht nur verbal und semantisch, sondern symbolpolitisch und monumental ausgetragener Konflikt zwischen religiös und areligiös konnotierter Nationsidee so in keiner der anderen Kapitalen stattgefunden hat.

Gegenüber den vielfachen symbolischen Affronts erwies sich der Katholizismus in Paris als durchaus resistent. Freilich blieben seine Voten überwiegend defensiver Natur und wurde hier unter Aufbietung aller Kräfte die Exklusion aus der republikanischen Nation zu verhindern gesucht. In der erhitzten Symboldebatte verfügten die katholischen Repliken nicht immer über die ruhige Souveränität, für konkurrierende, religiös-konfessionelle Konnotationen der »nation« zu werben, sondern hielten sich oft mit der Umkehrung von Obskurantismusvorwürfen gegen ihre Kritiker auf. Etwa mit der »dieu«, »roi«, "patrie«-Formel waren die Wertekoordinaten der »France catholique« gleichwohl unmißverständlich benannt.

Zwar war auch in London der Katholizismus monumental präsent. Die im Gegensatz zu Paris konsensuale Inszenierung des Newman-Denkmals 1896 wurde von der anglikanischen Staatskirche allerdings nicht nur vor dem Hintergrund der offiziösen Symbolkonkurrenz mit dem Arnold-Denkmal in Westminster weitgehend kritiklos akzeptiert. Es kamen auch anglikanische Deuter im Zeremoniell selbst zu Wort und warteten mit Inklusionsparolen auf, indem sie ein konfessionsindifferentes christliches Bekenntnis als gemeinsamen Sinnbezug für die nationale Ordnung umschrieben und die Exklusionsrhetorik auf den areligiösen Teil der Gesellschaft verlagerten. Die dem Anglikanismus nahestehende Presse hat zwar auf der primären Affinität der Nation und des "British Empire« zur Established Church beharrt, andererseits aber keinen auch nur annähernd so polemischen Ton entwickelt, wie dies für die laizistischen Attacken gegen den Katholizismus in Paris der Fall gewesen ist. Anders als in Paris und London, indessen nur partiell repräsentativ für ein faktisch bikonfessionelles Reich, ist demgegenüber in Berlin der Katholizismus nicht zu öffentlicher Symbolmacht gelangt.

Mit dem Pariser Coligny-Denkmal meldete sich schließlich auch der Protestantismus symbolisch zu Wort. Dem antiklerikalen Affekt des republikanischen Liberalismus und Linksradikalismus versuchten die Denkmalstifter den Protestantismus zu entziehen, solidarisierten sich andererseits freilich keines- 
wegs mit der katholisch-konservativen Position als Quintessenz eines französischen Bekenntnisses. Statt dessen sollte der Katholizismus nicht anders als sonstige divergente religiöse und politische Loyalitätsverbände über Toleranzpostulate in ein nationales Ganzes eingebunden werden. Affinitäten zur Dezentralisienung und antifranzösische Allianzbildungen blieben demgegenüber die historischen Verdikte, mit denen Konservative die Coligny-Figur belastet sahen und damit in geschickter Anspielung auf 1871 und die französische Erniedrigung durch den protestantischen preußisch-deutschen Feind den Protestantismus des nationalen Verrats zu bezichtigen versuchten.

Nachdrücklicher, als dies für Paris gelten konnte, stand in Berlin der Protestantismus im programmatischen Mittelpunkt der Zeichensetzungen mit dem Luther-Denkmal von 1895 und stellte sich mit Verve in die Nähe des Obrigkeitsstaates. Dabei erschien das Reformationsereignis komplett säkularisiert und dem borussianischen Geschichtsmythos vom aufsteigenden PreußenDeutschland einverleibt. Das Calvin-Denkmal von 1885 bildete demgegenüber den Sonderfall einer Inklusionsprogrammatik, mit dem die Nachfahren der hugenottischen Minderheit sich mit geschichtsklitternden Simplifizierungen ihrerseits der preußischen Aufstiegslegende zuordneten. Die europäische Dimension des hugenottischen Exodus nach 1685 aus Frankreich und die vielfachen Assimilierungskonflikte der andersnationalen Minderheit blieben um dieser Inklusionsfiktion willen ausgeblendet.

In je spezifischen Deutungskontexten entsprach dem Pariser Coligny- und dem Berliner Luther-Denkmal nun die Londoner Tyndale-Figur. Ausbleibender Widerspruch zum Denkmal war hier allerdings nicht zuletzt dem äußerst bescheidenen Einweihungsritual geschuldet. Gegenüber anderen Konfessionen und deren Anspruch auf national intendierte öffentliche Denkmalehrung erwies sich die Londoner Denkmallandschaft damit als deutlich toleranter und inklusiver, als dies für Paris oder Berlin gelten konnte. Dem gelungen inklusiven Festarrangement anläßlich der Einweihung des methodistischen WesleyDenkmals 1891 entsprachen um Anschlußfähigkeit und Kompatibilität bemühte Deutungen der Figur und ihrer Relevanz für die Nation. Von anglikanischer Seite her zeigte man sich bereit, die konfessionelle Zersplitterung in Denominationen nicht sofort als Statusgefährdung für die Staatskirche, sondern als Symptom für einen spirituellen Reformbedarf zu deuten und zumindest dem konfessionellen Pluralismus gleichsam regenerativen Sinn abzugewinnen. Vor diesem Hintergrund ließ sich umgekehrt auf methodistischer Seite ohne allzu großen Affront die These vertreten, daß der Wesleyanism für eine engagierte Inklusion der gesellschaftlich Marginalisierten eintrat, die mindestens eine soziale, wo nicht sozial- und reformpolitische Valenz hatte. In der spirituellen Kompensation jener sozialen Ungleichheit, die als Negativeffekt der Modernisierung aufgetreten war, bestand demnach der historische Beitrag des evangelikalen Methodismus im Rahmen der voranschreitenden inneren Nati- 
onsbildung Großbritanniens im 19. Jahrhundert, die konfessionell indifferent bestätigt werden konnte. Die Konvergenz ordnungspolitischer Vorstellungen blieb freilich eine zentrale Voraussetzung für die Harmonie der Denkmaldeuter, denn die Inklusionspostulate der Methodisten zielten - symptomatisch sichtbar in der einmal lautgewordenen Forderung nach offiziöser Anerkennung des Dissent durch die Queen - immer auf den Konsens mit der monarchischen Nation. Der konsensualere Eindruck der Londoner Denkmallandschaft speiste sich also zumindest im Blick auf die konkurrierenden Denominationen aus einer grundlegenden ordnungspolitischen Konvergenz. 